Article

\title{
Geospatial Analysis of Rain Fields and Associated Environmental Conditions for Cyclones Eline and Hudah
}

\author{
Corene J. Matyas (D) and Sarah VanSchoick*(D) \\ Department of Geography, University of Florida, Gainesville, FL 32611, USA; matyas@ufl.edu \\ * Correspondence: sm.vanschoick@ufl.edu; Tel.: +1-3523-920-494
}

check for

updates

Citation: Matyas, C.J.; VanSchoick, S Geospatial Analysis of Rain Fields and Associated Environmental Conditions for Cyclones Eline and Hudah. Geomatics 2021, 1, 92-113. https://doi.org/10.3390/ geomatics1010008

Received: 30 December 2020

Accepted: 18 February 2021

Published: 24 February 2021

Publisher's Note: MDPI stays neutral with regard to jurisdictional claims in published maps and institutional affiliations.

Copyright: (c) 2021 by the authors. Licensee MDPI, Basel, Switzerland. This article is an open access article distributed under the terms and conditions of the Creative Commons Attribution (CC BY) license (https:// creativecommons.org/licenses/by/ $4.0 /)$.

\begin{abstract}
Tropical cyclones (TCs) that landfall over Madagascar and Mozambique can cause flooding that endangers lives. To better understand how environmental conditions affect the rain fields of these TCs, this study utilized spatial metrics to analyze two storms taking similar paths two months apart. Using a geographic information system, rain rates of $1 \mathrm{~mm} / \mathrm{h}$ were extracted from a satellitebased dataset and contoured to define the rain field edge. Average extent of rainfall was measured for each quadrant and asymmetry was calculated along with rain field area, dispersion, closure, and solidity. Environmental conditions and storm intensity were analyzed every six hours. Results indicate that although both TCs intensified prior to first interaction with land, stronger vertical wind shear experienced by Eline was associated with higher asymmetry and dispersion. Additionally, rain fields were less solid although the center was mostly enclosed by rain. Storm shape was altered as both storms tracked over Madagascar, with Hudah recovering more quickly. Moisture increased for both storms and shear decreased for Eline, allowing it to become more centered and solid, and grow larger. Relationships between intensity, land interaction, and rain field shape support the results of previous research and demonstrate the global utility of these metrics.
\end{abstract}

Keywords: GIS; spatial analysis; tropical cyclones; rain fields

\section{Introduction}

Tropical cyclones (TCs) cause structural, environmental, economic, and societal damages around the world due to their fast winds, storm surges, and flooding rainfall [1]. The most familiar classification for these systems is according to their intensity, which refers to the maximum sustained wind speed, although this typically happens in a small area near the center of the storm. Size is measured by the radial extent of gale-force $(17 \mathrm{~m} / \mathrm{s})$ winds, which occur over a much larger area. Although abundant rainfall from TCs contributes to flooding that endangers lives and livelihoods [2], no standard metric exists to categorize TCs according to their rain field size. The Dvorak technique utilizes the spatial patterns of TC clouds to determine storm intensity [3]. As such a standard is not in place to measure the spatial properties of TC rain fields, continued efforts along these lines are warranted.

Countries in southeastern Africa such as Mozambique and Madagascar are impacted by TCs that can reach wind speeds of over $67 \mathrm{~m} / \mathrm{s}$ and produce flooding rainfall as recently occurred with Cyclones Kenneth and Idai in 2019 [4,5]. TCs can make landfall over Madagascar and/or Mozambique multiple times in a single season [6]. Rural Mozambique is spotted with communities of farmers that depend entirely on agriculture [7]. Drought is detrimental to their income, yet large amounts of rainfall can be just as damaging [8]. Many factors such as sea surface temperatures (SSTs) and interannual variations in atmospheric circulation contribute to rainfall variability in the area, but TCs have caused much damage and many lives have been lost when they produce flooding rainfall $[1,9,10]$. Wind and rainfall properties of TCs affecting other parts of the globe have been studied by hundreds of researchers, however, less research has focused on TCs that affect African countries.

Although TC frequency and landfall occurrence have been documented globally, the few studies that have examined the rainfall extent of these storms focused on the 
Atlantic basin [11-13]. These studies examined TCs moving over large landmasses and did not look at how topography of island nations might affect rainfall extent and rain field shape. Previous research showed that TCs may expand or contract in rainfall extent when interacting with land [12]. The amount or extent of rainfall produced by a landfalling TC changes due to environmental factors such as topography and loss of heat and moisture from the sea [14]. To our knowledge, no studies have examined rainfall extent for TCs that form over the Southwest Indian Ocean (SWIO).

There are multiple dynamic and thermodynamic conditions that must exist for a TC to form and these conditions must persist for the storm to be maintained and/or intensify [15]. Of these, much previous research has examined how vertical wind shear (VWS) affects structure and rainfall asymmetry. When the winds in the upper troposphere are too strong, they cause the TC to tilt and this causes its rainfall regions to develop more strongly on the side of the tilt (downshear), while rainfall decreases on the opposite upshear side [16]. Lonfat et al. [17] included shear as a key predictor of TC rainfall in their statistical model. Corbosiero and Molinari [18] and Chen et al. [19] found that VWS $>5 \mathrm{~m} / \mathrm{s}$ negatively affects TC organization. Lonfat et al. [20] suggested precipitation distribution is asymmetric toward the leading edge of TCs in the Southern Hemisphere.

Key thermodynamic conditions needed for TC development include sufficient moisture in the environment surrounding the storm, and high SSTs generally $>26.5^{\circ} \mathrm{C}$. Although it has been studied less than VWS, water vapor available in the environment surrounding a TC is crucial to storm development and sustenance. In a modeling study, [21] found that higher relative humidity (RH) values in the environment surrounding a TC led to increased wind field size, while an observational study by [11] found that higher RH values corresponded to larger extent of rain fields on the western sides of hurricanes making landfall over the U.S. On the other hand, [22] found that dry air can limit the ability of a TC to intensify and introduce asymmetries in convection. SSTs are tightly coupled with environmental humidity in the tropics [23]. Evans et al. [24] found that TCs over deep and warm waters had higher area-averaged rainfall than when over cooler waters. Lin et al. [25] found that higher SSTs corresponded to higher TC rain rates.

Both Madagascar and Mozambique lie between $10^{\circ} \mathrm{S}$ and $30^{\circ} \mathrm{S}$ (Figure 1) in a region where the thermodynamic and dynamic conditions necessary for TC development occur during the late spring, summer, and early autumn [26]. Rainfall is highly variable during these months due to effects of the Intertropical Convergence Zone (ITCZ), which moves across these countries during austral summer $[27,28]$. When TCs move over Madagascar and Mozambique, they encounter different topography (Figure 1). Madagascar is characterized by a mid-island plateau $1600 \mathrm{~m}$ high with peaks up to $2600 \mathrm{~m}$ which includes the Malagasy Mountains in the northwest and Maromokotro on the north of the island having the tallest point of $\sim 2800 \mathrm{~m}$ above sea level [14]. While moving over these steep mountains, TCs weaken but can re-intensify once on the leeward side due to development of the lee rotor $[14,29]$. On the other hand, Mozambique has a low-lying coastline that extends more than $200 \mathrm{~km}$ westward before increasing to the Manica Plateau, Lebombo Mountains in the south, and Namuli Mountains in the north. The Mozambique Channel is between these countries, whose coastlines are $430-1050 \mathrm{~km}$ apart, and its warm waters provide energy to help TCs form or intensify, while VWS remains relatively low [30].

Massive flooding often occurs in rural Madagascar and Mozambique during TCs [7]. Soil rapidly erodes when immense amounts of rainfall are received. Cycles of drought and TCs create landslides and destroy crops which are instrumental in the livelihoods of the people [31]. Poverty in Mozambique can be exacerbated by a highly variable climate [8]. Some communities have responded to the flooding risks by relocating to higher ground where consequently, they are more prone to drought [32]. Timing of TC rainfall is instrumental to food security for Madagascar farmers with regard to water budget planning and landslides - too little can deprive crops while too much can cause landslides and flood fields during planting season forcing a delay in harvest [7]. 


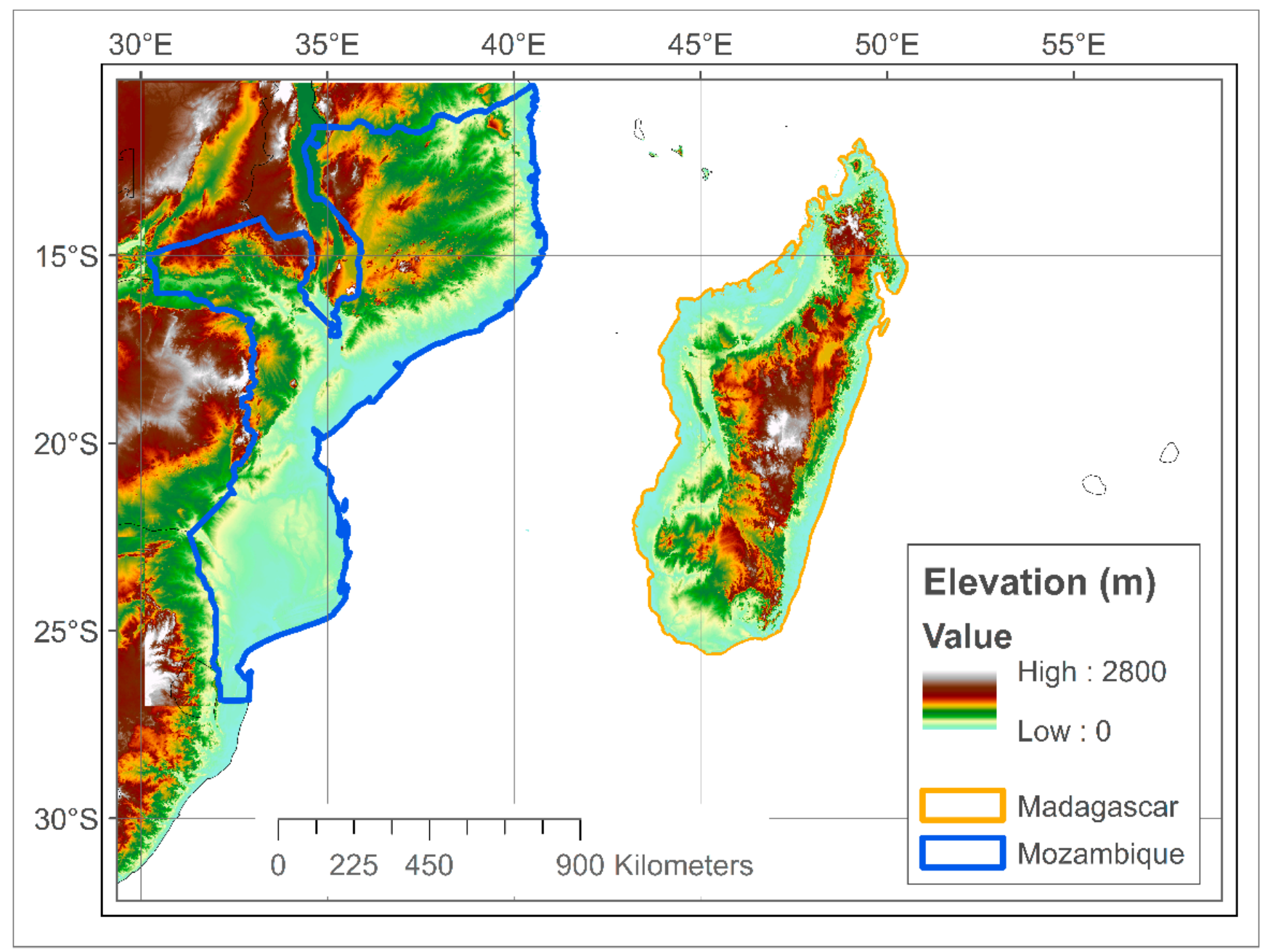

Figure 1. Topography of Mozambique and Madagascar.

During 1950-1999, fewer than 5\% of TCs that formed over the SWIO made landfall over southern Africa's east coast [33]. Yet in 2000, Cyclones Eline and Hudah both made landfalls over Madagascar and Mozambique (Figure 2). Their tracks were atypical as the majority of TCs recurve west of Madagascar or turn south once entering the Mozambique Channel and recurve [26,30,34]. Fitchett and Grab [35] state that only 5\% of TCs make landfall over both countries, although their study does not include Hudah. A La Niña was occurring which is typically associated with more zonal TC tracks [36]. Eline formed near the coast of Indonesia on 3 February and made landfalls over Madagascar and Mozambique on 17 and 22 February, respectively. Southern Africa was well above-normal in terms of rainfall in the weeks prior to Eline's passage. Reason and Keibel [33] found that latent heat flux was higher than normal which likely contributed to Eline's intensification prior to its Mozambique landfall and the record rainfall it produced. Hudah formed on 22 March, making landfall over Madagascar (Mozambique) on 2 (8) April. The effects caused by Cyclones Eline and Hudah were widespread and devastating. Eline brought $>20 \mathrm{~cm}$ per day of rain to an already wet region of Mozambique [36]. After Eline, initial estimates showed that over 1 million people were affected with 300,000 homeless or displaced, $>69$ deceased, and major economic impacts to agriculture and infrastructure [37]. According to the Food and Agriculture Organization (FAO): Special alert \#301 (2000), floods caused by Eline drastically affected food security [37]. An estimated 150,000 hectares ( 370,000 acres) of crops were lost due to flooding from Eline. In South Africa, farmers lost $>50 \%$ of their exportable products [38]. Rain fields from Cyclone Hudah crossed over land just five weeks after rainfall from Eline stopped. Hudah contributed at least 17 more deaths, 
$\sim 100,000$ homeless, $\sim 300,000$ displaced, and further crop damage in already devastated areas [39].

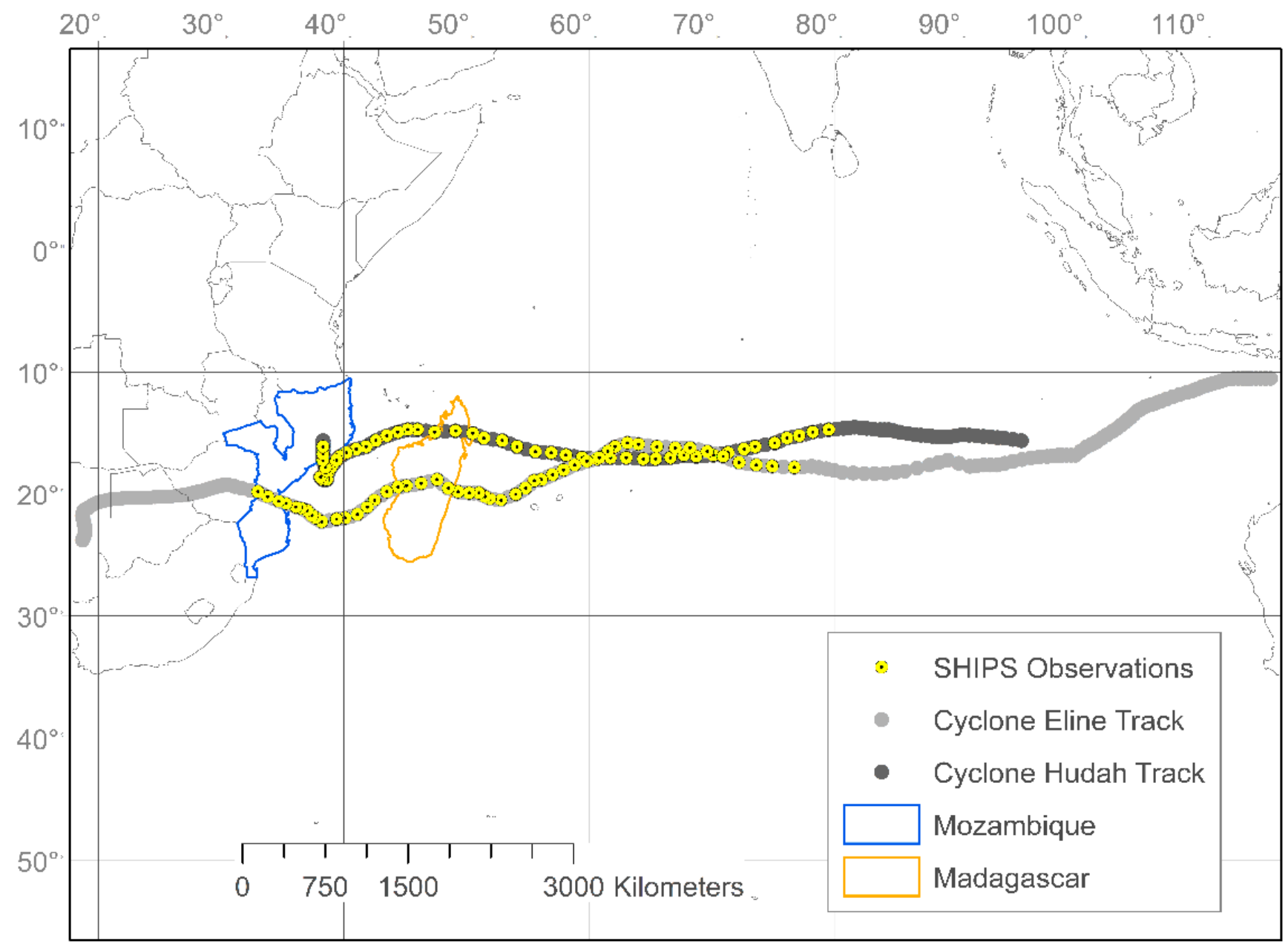

Figure 2. Tropical cyclones (TC) whole-life tracks for Cyclones Eline and Hudah (2000) and Statistical Hurricane Intensity Prediction Scheme (SHIPS) observation points included in the analysis.

The importance of environmental conditions in the development of TC rain fields, and the limited studies about rain fields of TCs over the SWIO, were considered when developing the current study. We hypothesized that rain field extent will be large and more symmetrical, and the rain fields will completely enclose the circulation center, be centered on the circulation center, and have high solidity as the TC experiences low vertical wind shear and high values of relative humidity while moving over warm waters. Landfall and/or encountering strong vertical wind shear should associate with an asymmetrical and dispersed rain field that does not completely enclose the storm center. We explored these proposed relationships by comparing Cyclones Eline and Hudah which intensified into the equivalent of a hurricane and took similar trajectories over the SWIO, making landfalls over Madagascar and Mozambique (Figure 1). We tested the hypothesis by comparing shape metrics including asymmetry, solidity, dispersion, closure, and area covered by rain. Additionally, we analyzed environmental conditions including SST, vertical wind shear, and relative humidity between the storms, for both before and after rain field interaction with land using non-parametric statistical tests.

\section{Materials and Methods}

Rain gauge data are not spatially or temporally consistent for either Madagascar or Mozambique [40]. Thus, we defined rain rates produced in both TCs using data from the 
Tropical Rainfall Measuring Mission (TRMM) 3B42 product [41]. Data from the TRMM's microwave imager and multi-sensor infrared-based datasets are calibrated and combined to produce a snapshot of rain rates every three hours with a $0.25^{\circ}$ spatial resolution with coverage $50^{\circ} \mathrm{N}-\mathrm{S}$. The rain rates are verified using ground observations on a monthly scale. Numerous researchers have utilized the TRMM 3B42 dataset to examine rainfall production for TCs globally and rainfall over the study region [8,40,42-44].

The 3-hourly positions, intensity, and speed of forward motion of each TC were taken from the International Best Track for Climate Stewardship (IBTrACS) dataset [45]. Intensity estimates from the Bureau of Meteorology and La Reunion are based on a 10-min sustained speed. Original values are in $\mathrm{kt}$, which we converted to $\mathrm{m} / \mathrm{s}$. Intensity values are satellite estimates which are subject to some variability in precision especially over land, and maximum sustained wind speeds are not estimated once a TC becomes too weak.

Data pertaining to VWS, moisture, and SSTs were taken from the Statistical Hurricane Intensity Prediction Scheme (SHIPS) dataset for an equal number of observations for each TC (Figure 1) [46]. The SHIPS dataset contains more than 100 variables that are used in a statistical model to help forecast TC intensity. Raw values taken from the Global Forecast System are analyzed every six hours by averaging values in a ring extending $200-800 \mathrm{~km}$ from the TC's circulation center. This removes the core of the storm from the analysis so that conditions at the storm's edge and in its surrounding environment are considered. For VWS, wind vectors from 200 and $850 \mathrm{hPa}$ are subtracted and then averaged over the ring to produce a value for the speed and direction. We combine speed and heading to determine $\mathrm{u}$ (zonal) and $\mathrm{v}$ (meridional) components of the deep-layer shear. For $\mathrm{RH}$, values are averaged over 850-700 hPa (RHLO), 700-500 hPa (RHMD), and 500-300 hPa (RHHI). Reynold's SSTs are utilized to examine ocean conditions.

We employed a geographic information system (GIS) to analyze the spatial patterns of rain rates produced by both TCs. We selected a threshold rain rate to delineate the outermost edge of each TC's rain field. Lonfat et al. [20] found that rain rates for TCs over the Southern Indian Ocean peaked at $1 \mathrm{~mm} / \mathrm{h}$. After a sensitivity analysis utilizing rates of 1,2 , and $2.5 \mathrm{~mm} / \mathrm{h}$, we found that using $1 \mathrm{~mm} / \mathrm{h}$ to define the edge of the rain field produced the most reliable results across the TCs. In many cases, higher rain rates produced regions that were too small for analysis. Next, we converted smoothed contours to polygons and determined the distance of each polygon's centroid from the TC's circulation center (Figure 3a). We only included polygons with centroids $<500 \mathrm{~km}$ from the TC center to exclude rainfall produced from other weather systems [42].

These regions bounded by $1 \mathrm{~mm} / \mathrm{h}$ rain rates were then examined in two ways. First, the extent of the outermost edge of the rain fields was calculated for each storm quadrant. Every $1^{\circ}$ around the storm center, radial lines extended $750 \mathrm{~km}$ (Figure 3b). At every location where a radial intersected with a polygon's edge, the location of this intersection was recorded. The farthest intersection along each line was retained and the 90 measures in each quadrant were averaged. The quadrants were placed according to cardinal directions: northwest (NW), southwest (SW), southeast (SE and northeast (NE) [11,47]. As the TCs generally moved east to west, the western quadrants contained the leading edge of the storm, with the southwest quadrant generally carrying the highest wind speeds as it was the left front quadrant. We then measured asymmetry by subtracting the quadrant with the largest average rainfall extent from the quadrant with the smallest average rainfall extent. Intersecting the rain field polygons with land allowed us to determine the time that the rain fields first crossed over land (Figure 4) and we examined differences in atmospheric conditions and rain field patterns before and after each TC's rain field first intersected Madagascar (Figure 5a,b). As data pertaining to the environmental conditions are available every six hours, we only analyzed rain rates at these matching times. 


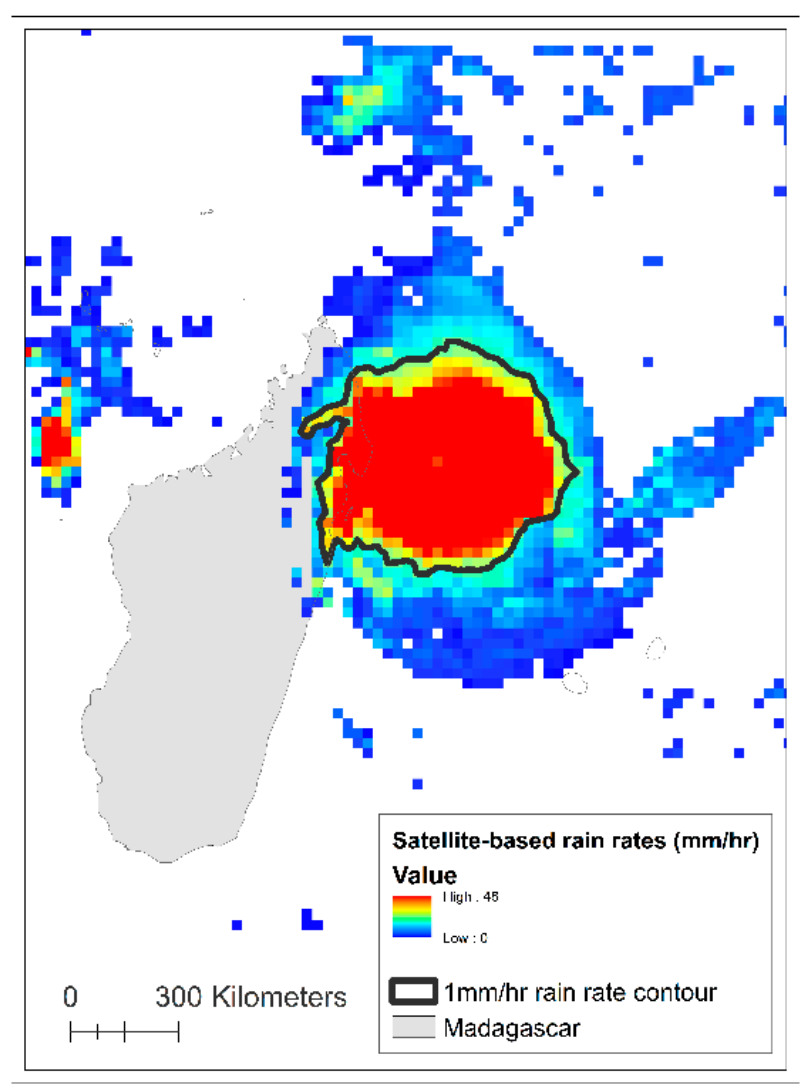

(a)

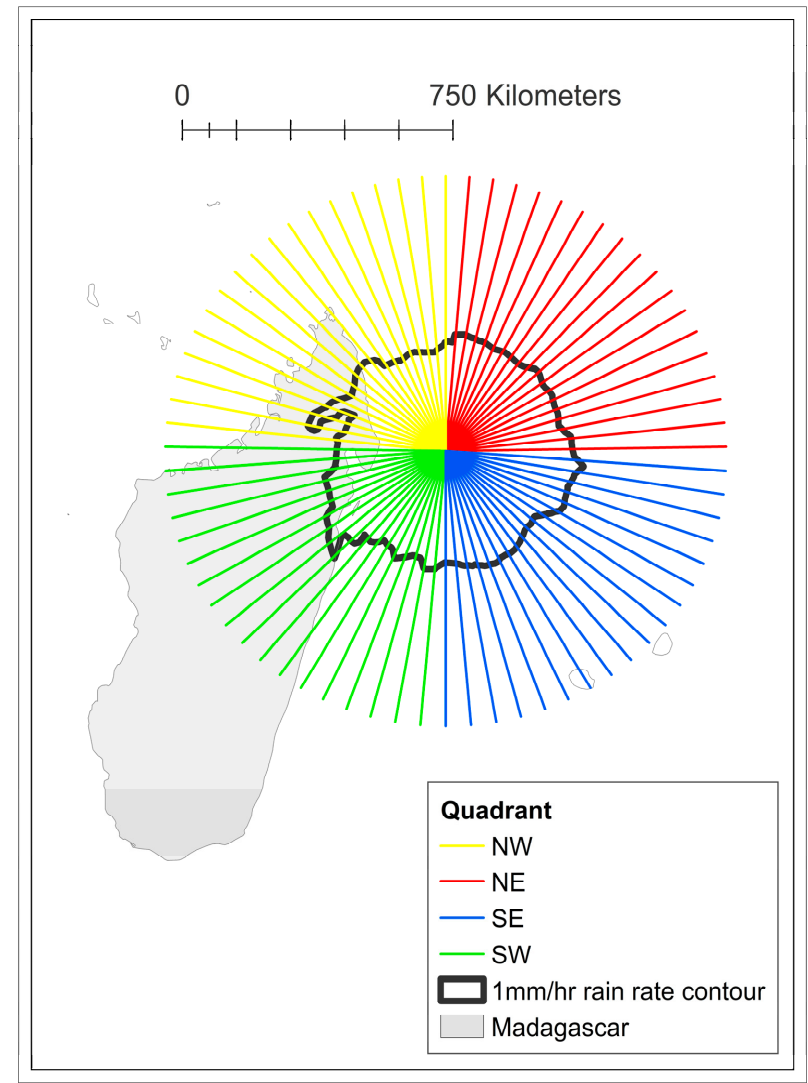

(b)

Figure 3. (a) Rain rates for Cyclone Hudah with black contour enclosing rates equal to or greater than $1 \mathrm{~mm} / \mathrm{h}$; (b) radial lines extending $750 \mathrm{~km}$ outward from the storm's center to intersect the $1 \mathrm{~mm} / \mathrm{h}$ contour. Lines shown every $5^{\circ}$ from the eye for visualization purposes. Measurements averaged each quadrant.

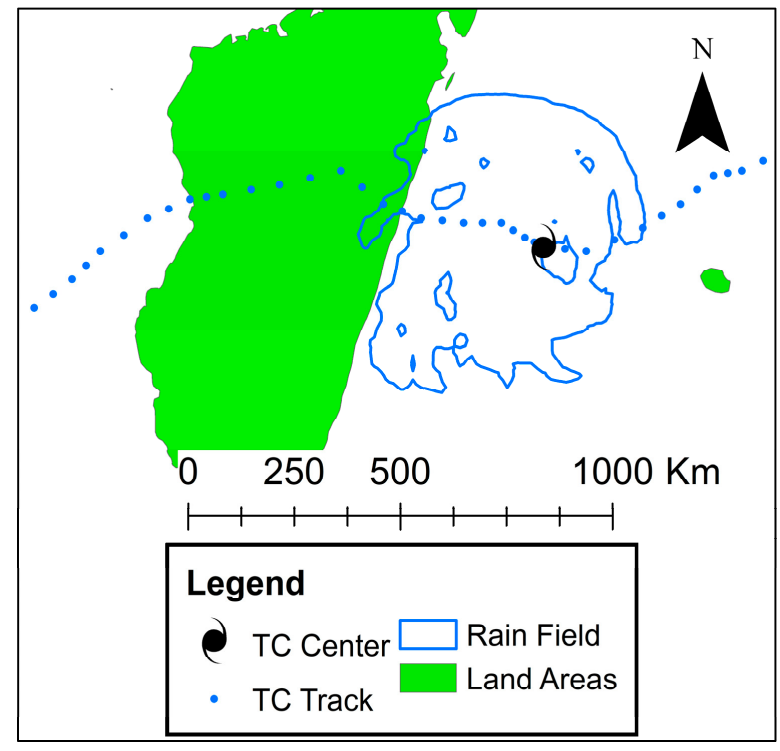

(a)

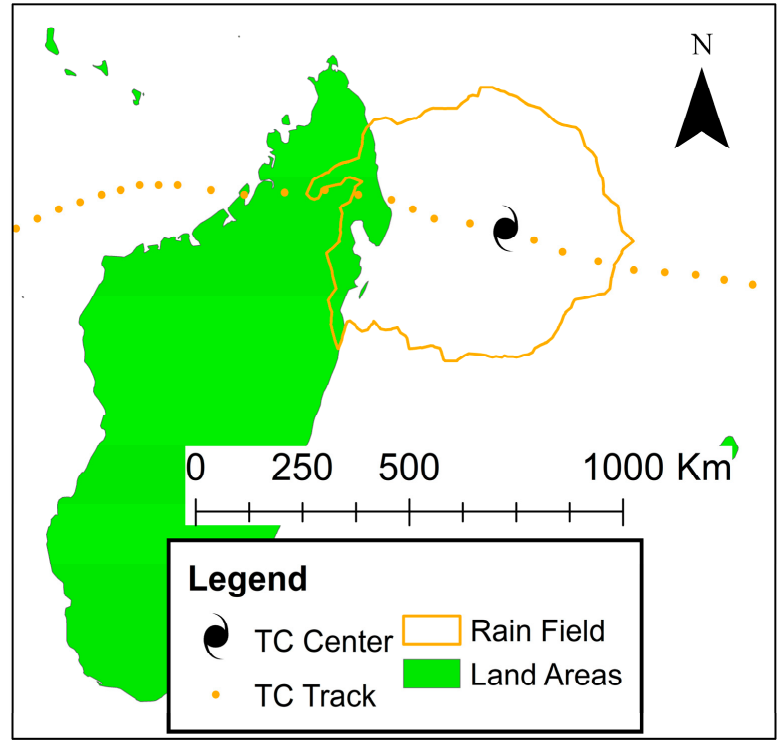

(b)

Figure 4. Cont. 


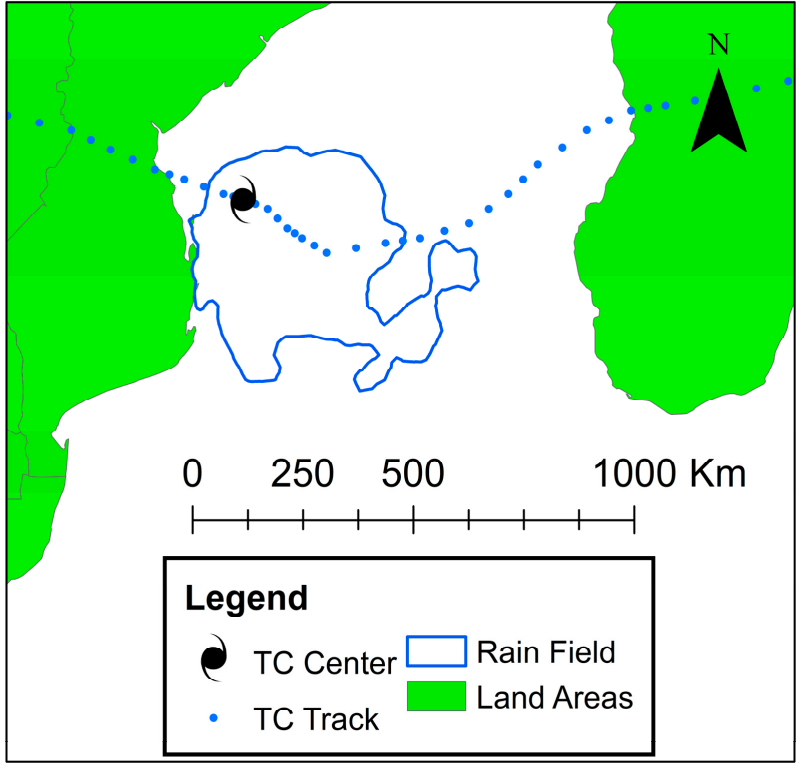

(c)

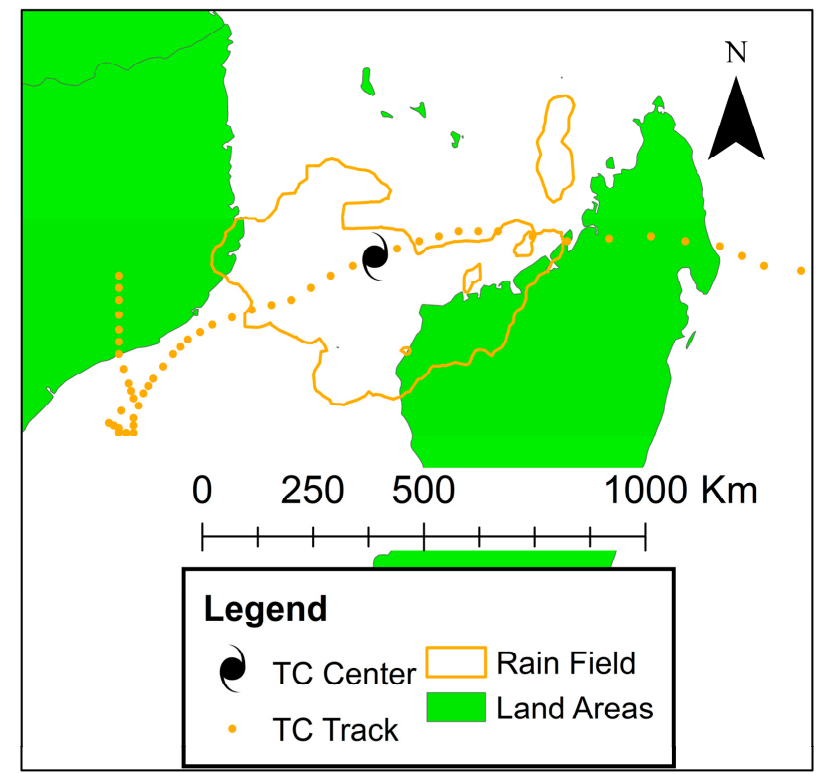

(d)

Figure 4. Rain fields at closest observation to time to when TC begins interacting with land for (a) Eline near Madagascar at 16 February 1200 UTC; (b) Hudah near Madagascar at 2 April 900 UTC; (c) Eline near Mozambique at 21 February 1500 UTC; and (d) Hudah near Mozambique at 4 April 300 UTC.

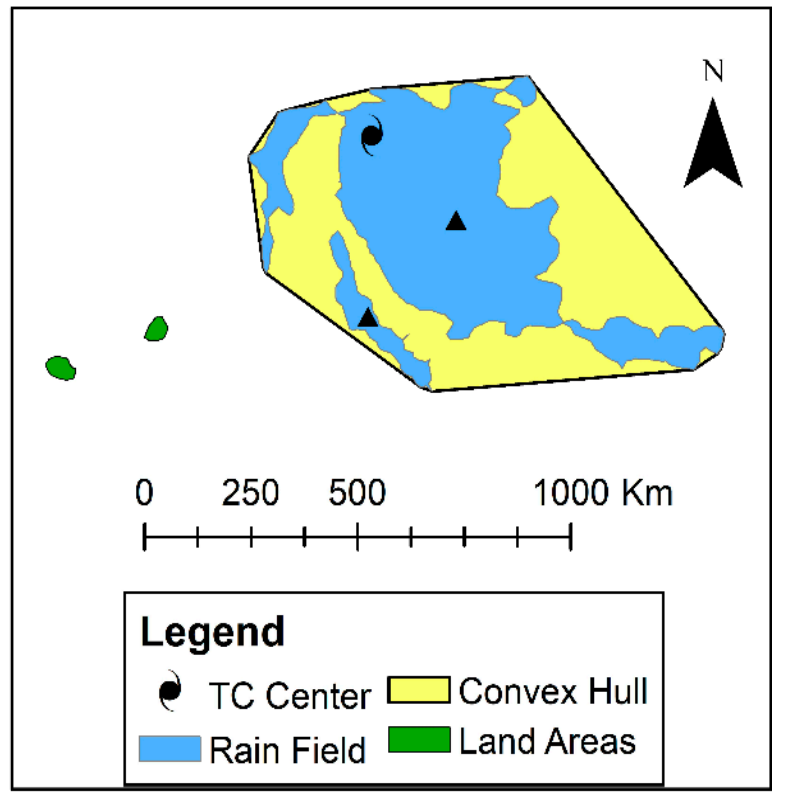

(a)

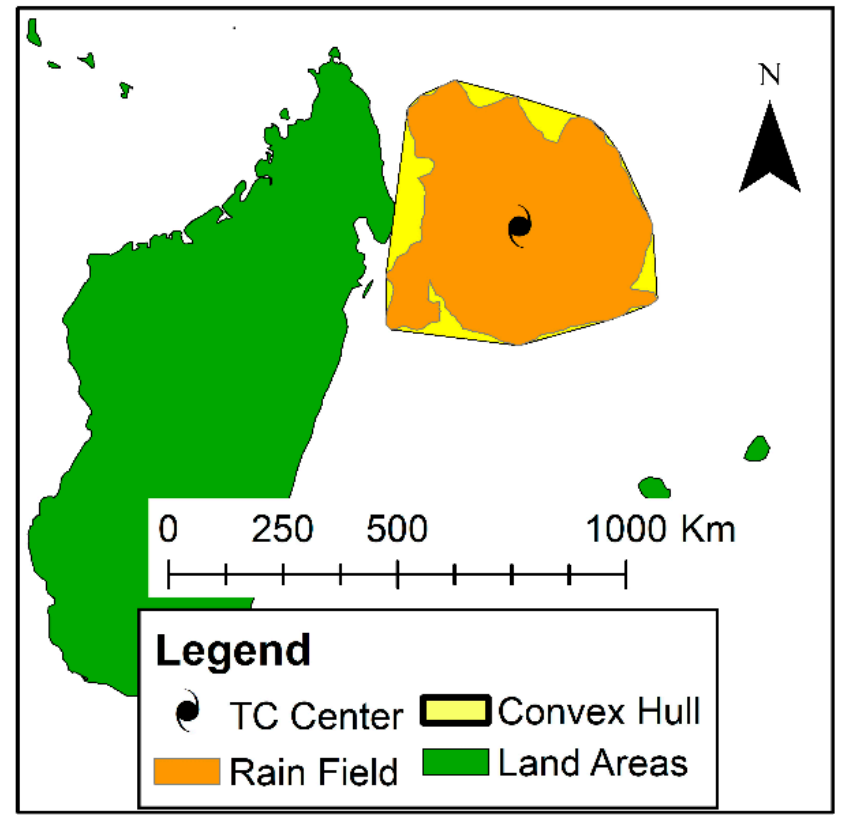

(b)

Figure 5. (a) Rain fields of Eline at 13 February 1200 UTC displaying complete closure but high dispersion and low solidity. Triangles represent polygon centroids used to calculate dispersion from the TC center; (b) Rain fields of Hudah at 2 April 600 UTC displaying complete closure with low dispersion and high solidity. Polygon centroid is co-located with TC center.

The second set of calculations examined multiple measures of TC compactness by considering the entire rain field rather than dividing it into sections. After calculating the area occupied by each rain field, we related the area of the rain fields to that of a convex hull, which is the simplest polygon that can encompass it (see Equation (1)). The simple shape should have a larger area than the more complex actual rain field (Figure 5a) that 
could also be comprised of multiple polygons that would leave some of the hull unfilled (yellow areas Figure 5a). Higher solidity values indicate that the rain field fills most of its convex hull (Figure 5b). This metric is called Area index by [48]

$$
S=\frac{\text { Area Rain Field }}{\text { Convex Area }}
$$

Dispersion measured the degree to which the rain field was centered over the TC's circulation center. We used a search radius $\left(r_{\text {search }}\right)$ of $500 \mathrm{~km}$ and calculated the ratio of the centroid radius $\left(r_{\text {centroid }}\right)$ to the search (see Equation (2)). The number of polygons (NP) was determined and dispersion was calculated individually for each rainfall polygon, and then the values of all polygons were summed to get the final value, with larger polygons receiving more weight in the calculation. The theoretical range of this metric is from 0 to 1 with 0.5 indicating that the average centroid position is $250 \mathrm{~km}$ from the storm center, which is similar to Figure 5a. In Figure 5b, dispersion is 0.04 as the centroid of the lone polygon is almost perfectly aligned with the TC's circulation center. Dispersion has been utilized to examine TC rainfields using data from TRMM 3B42 data for the entire TC lifecycle and from higher-resolution data detected by ground-based radars [49-52].

$$
D=\sum_{i=1}^{N P} \frac{\text { Area }_{i}}{\sum_{i}^{N P} \text { Area }_{j}}\left(\frac{{ }^{r} \text { centroid }, i}{{ }^{r_{\text {search }}}}\right)
$$

While dispersion measured the radial distribution of the rain fields with respect to the storm center, closure measured the tangential distribution. As in the extent calculations, radial lines were extended outward from the TC center every $1^{\circ}$ around a circle (Figure $3 \mathrm{~b}$ ). Each radial that intersected a rain field polygon was noted and all intersections were summed and divided by the maximum possible of 360 (see Equation (3)). We also employed an exclusion zone of $25 \mathrm{~km}$ around the TC center due to the rather coarse resolution of the 3B42 data which hinders its ability to detect the eye in fine resolution, and for timing offsets between the TRMM 3B42 images and the TC positions. Closure of 1.0 indicates that rain fields completely enclose the TC center (Figure 5), while a value of 0.5 means that $180^{\circ}$ contains rainfall. Closure was originally developed by [53] and called rain field arc-length and has been calculated for Atlantic Basin TCs near to and over land with high-resolution data from ground-based radars $[50,52,53]$.

$$
C=\frac{\text { no. } 1^{\circ} \text { angles intersecting polygons }}{360}
$$

In this study, we represented the data according to the time relative to when the rain fields first cross over land (Figure 4a,b). Negative values in the time series plots indicate time prior to crossing Madagascar. We did not utilize the entire storm's history as Eline lasted for 13 days more than Hudah (Figure 2). As we also contrasted the rain field extent and atmospheric conditions before and after land interaction, we began our analysis at a time when there was a fairly even number of observations before and after land interaction, which also captured the time when the tracks were the most similar as the storms approached Madagascar. Observations occurring before the rain fields first interact with land are termed Period 1, while those after first land interaction occur during Period 2.

We utilized two types of nonparametric statistical tests to compare the two TCs and associate atmospheric conditions with rain field extent. We first employed a Mann-Whitney $U$ test, which determines similarities between two independent samples, to compare the two TCs according to the rain field spatial patterns, maximum sustained wind speed, the velocity of the $u$ and $v$ components of the VWS, RH, and SSTs. Correlations among intensity, environmental conditions, and rain field extent, asymmetry, and shape were calculated using the Spearman's rank correlation coefficient. When plotting time series graphs of the variables, we noted changes that seemed to coincide with the time that the rain fields first crossed over land. Thus, we employed Mann-Whitney $U$ tests within each storm 
to test variables before and after first land interaction, and to compare the storms with each other before and after this interaction. We utilized a 95\% confidence level $(\alpha=0.05)$ to test the null hypothesis that the independent samples were statistically similar for all Mann-Whitney $U$ tests, and to determine that a coefficient was statistically significant in the correlation analyses.

\section{Results}

\subsection{Rain Field Spatial Patterns}

On average, the rain fields of Eline extended farther from the storm center than did those of Hudah, save for the northeast quadrant (Table 1). Eline was also more asymmetric than Hudah. However, only the differences in the southeast quadrant and asymmetry were statistically significant. Ranges of rainfall asymmetry in Eline were 89-290 km compared to Hudah with a range of 72-202 km. Eline and Hudah were most dissimilar in the asymmetry metric $60 \mathrm{~h}$ before interaction with land (Figure 6). When Hudah's rain fields began interacting with land, a general increase in asymmetry trended for $24 \mathrm{~h}$ before the storm moved over the Mozambique Channel. Rain fields in both storms trended toward symmetry before making their second landfall over Mozambique. The rain field of Hudah was most often largest in both the NE and SE quadrants, which were behind the storm center. Although the rain field of Eline was overwhelmingly largest in the SE quadrant, its largest quadrant at the time of first land interaction was the northwest quadrant, which was one of the forward quadrants given the westward motion of the storm. Having the largest rain field extent in one of the forward quadrants means that rainfall started over land sooner relative to landfall for Eline than for Hudah (Table 2).

Table 1. Median values for extent of rain fields in each quadrant, overall storm average, and asymmetry for Eline and Hudah, and $p$-values from Mann-Whitney $U$ tests. Bold values indicate statistical significance at the $95 \%$ confidence level. Eline $n=51$; Hudah $n=49$.

\begin{tabular}{cccc}
\hline Extent Measure & Eline Median $\mathbf{( k m )}$ & Hudah Median $\mathbf{( k m )}$ & $\boldsymbol{p}$-Value \\
\hline Southwest (SW) & 231 & 197 & 0.21 \\
Northwest (NW) & 204 & 201 & 0.76 \\
Northeast (NE) & 213 & 239 & 0.11 \\
Southeast (SE) & 267 & 233 & $\mathbf{0 . 0 1}$ \\
Overall Average & 230 & 222 & 0.31 \\
Asymmetry (Asym) & 144 & 119 & $\mathbf{0 . 0 1}$ \\
\hline
\end{tabular}

Table 2. Times for each TC when rain started over land, landfalls, and first observation time when center was over Mozambique Channel. Hours since rain began over Madagascar are included as they correspond to the $\mathrm{X}$ axis in the time series figures.

\begin{tabular}{ccc}
\hline & Eline & Hudah \\
\hline Rain Over Madagascar & 16 February 1200 UTC & 2 April 0900 UTC \\
\hline Landfall Madagascar & 17 February 1500 UTC & 2 April 1800 UTC \\
Time since first rain & $27 \mathrm{~h}$. & $9 \mathrm{~h}$. \\
\hline Center over Mozambique Channel & 18 February 1800 UTC & 3 April 0900 UTC \\
Time since first rain & $54 \mathrm{~h}$. & $24 \mathrm{~h}$. \\
\hline Rain over Mozambique & 21 February 1500 UTC & 4 April 0300 UTC \\
Time since first rain & $123 \mathrm{~h}$. & $42 \mathrm{~h}$. \\
\hline Landfall over Mozambique & 22 February 0600 UTC & 8 April 0600 UTC \\
Time since first rain & $138 \mathrm{~h}$. & $141 \mathrm{~h}$. \\
\hline
\end{tabular}




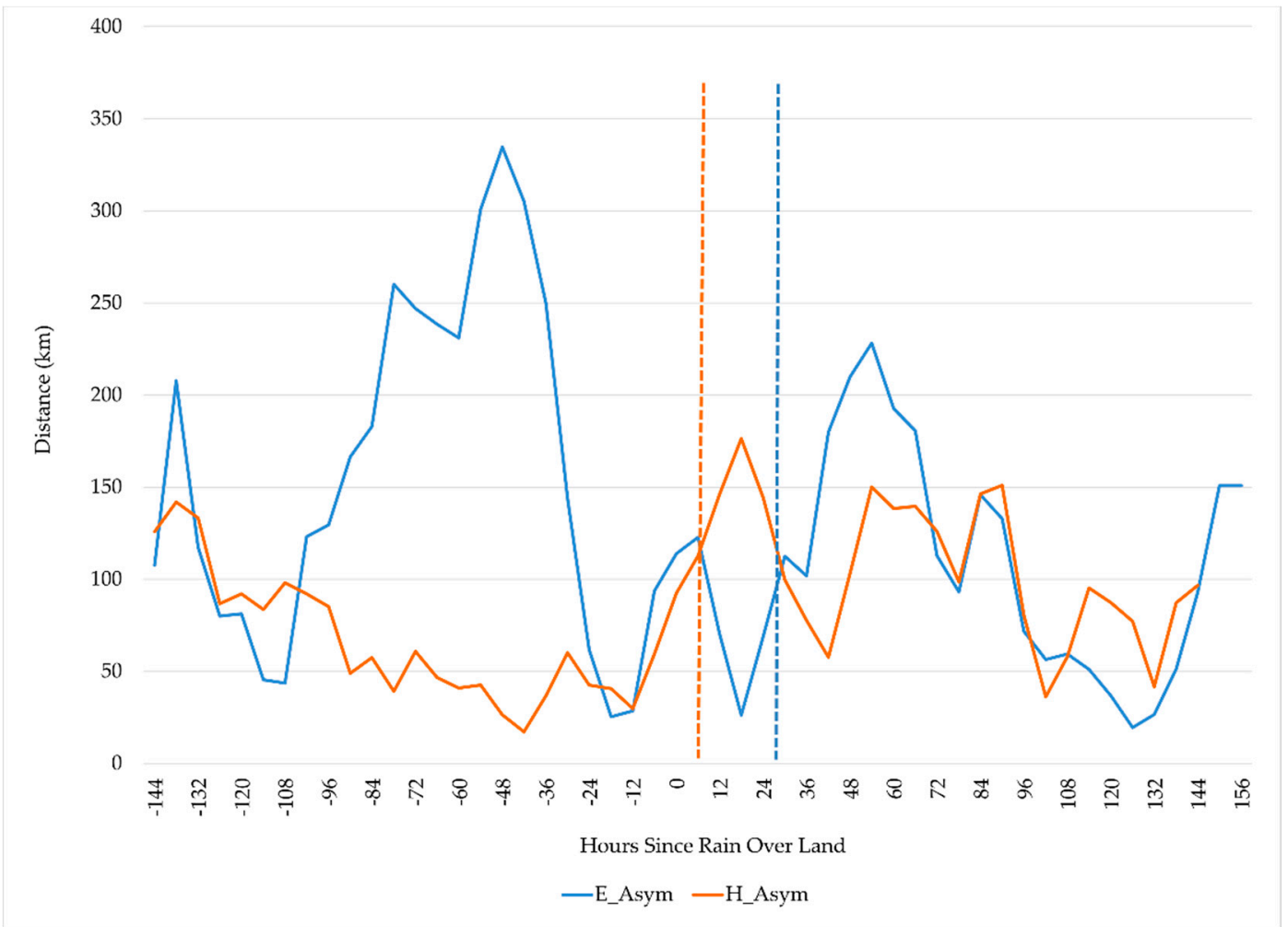

Figure 6. Time series of asymmetry $(\mathrm{km})$ for Eline and Hudah for hours since rain began over Madagascar. Vertical dashed lines represent landfall times over Madagascar.

As time series plots showed that differences in values occurred for some extents before first interaction with land as compared with after, values during these two periods were compared with Mann-Whitney $U$ tests. Results (Table 3) show that the northern half of Eline expanded during Period 2, with a resultant decrease in asymmetry. Although Hudah became more asymmetric, the individual quadrants did not show a statistically significant change in extent. In Period 1, Hudah's northern side was larger than that of Eline, while Eline was more asymmetrical. In Period 2, the only significant change was in the extent towards the northwest as Eline expanded and Hudah diminished.

Table 3. Median values of rain field metrics for times before and after rain began over Madagascar and $p$-values from Mann-Whitney $U$ tests comparing each storm with itself, the before observations of each storm, and the after observations of each storm. Eline before $n=24$, after $n=27$. Hudah before $n=23$, after $n=26$. Bold values are statistically significant at the 0.01 level.

\begin{tabular}{ccccccccc}
\hline Variable & Eline Per. 1 & Eline Per. 2 & $\begin{array}{c}\text { Hudah } \\
\text { Per. 1 }\end{array}$ & $\begin{array}{c}\text { Hudah } \\
\text { Per. 2 }\end{array}$ & $\begin{array}{c}\text { Eline Per. 1 } \\
\text { vs. Per. 2 }\end{array}$ & $\begin{array}{c}\text { Hudah Per. } \\
\text { 1 vs. Per. 2 }\end{array}$ & $\begin{array}{c}\text { Per. 1 Eline } \\
\text { vs. Hudah }\end{array}$ & $\begin{array}{c}\text { Per. 2 Eline } \\
\text { vs. Hudah }\end{array}$ \\
\hline NE $(\mathrm{km})$ & 185 & 250 & 238 & 241 & $<\mathbf{0 . 0 1}$ & 0.78 & $<\mathbf{0 . 0 1}$ & 0.82 \\
NW $(\mathrm{km})$ & 164 & 259 & 225 & 201 & $<\mathbf{0 . 0 1}$ & 0.09 & $<0.01$ & $<0.01$ \\
SW $(\mathrm{km})$ & 224 & 230 & 201 & 198 & 0.72 & 0.41 & 0.90 & 0.19 \\
SE $(\mathrm{km})$ & 294 & 247 & 231 & 243 & 0.25 & 0.37 & 0.30 & 0.94 \\
Asym $(\mathrm{km})$ & 137 & 102 & 57 & 98 & $\mathbf{0 . 0 5}$ & $<\mathbf{0 . 0 1}$ & $<\mathbf{0 . 0 1}$ & 0.94 \\
Area $\left(\mathrm{km}^{2}\right)$ & 178,887 & 258,536 & 187,905 & 181,473 & $\mathbf{0 . 0 2}$ & 0.84 & 0.66 & $<\mathbf{0 . 0 1}$ \\
Solidity & 0.67 & 0.66 & 0.82 & 0.76 & 0.53 & $<\mathbf{0 . 0 1}$ & $<\mathbf{0 . 0 1}$ & $<\mathbf{0 . 0 1}$ \\
Dispersion & 0.36 & 0.25 & 0.14 & 0.19 & $\mathbf{0 . 0 2}$ & $<\mathbf{0 . 0 1}$ & $<\mathbf{0 . 0 1}$ & 0.07 \\
Closure & 0.97 & 0.99 & 1.00 & 0.96 & 0.27 & $<\mathbf{0 . 0 1}$ & $<\mathbf{0 . 0 1}$ & 0.61 \\
\hline
\end{tabular}

While the rain field extent was similar in most quadrants when all observations were considered, all the polygon-based metrics were significantly different between Eline and Hudah (Table 4). With a larger area, Eline was also less solid than Hudah, less enclosed, 
and more dispersed. Taken together these metrics suggest that Hudah had a more filled rain field whose centroid averaged $85 \mathrm{~km}$ from the circulation center and that completely enclosed its circulation center. On the other hand, Eline's rain fields were larger but also less filled and more dispersed (centroid $\sim 140 \mathrm{~km}$ from the storm center). However, its closure was also very high, with 0.98 meaning that $\sim 353^{\circ}$ around the $360^{\circ}$ circle was covered by rain rates of at least $1 \mathrm{~mm} / \mathrm{h}$.

Table 4. Median values for polygon-based measures of rain field spatial patterns and $p$-values from Mann-Whitney $U$ tests. Bold values indicate statistical significance at the $95 \%$ confidence level. Eline $n=51 ;$ Hudah $n=49$.

\begin{tabular}{cccc}
\hline Polygon-Based Metric & Eline Median & Hudah Median & $\boldsymbol{p}$-Value \\
\hline Total Area $\left(\mathrm{km}^{2}\right)$ & 248,844 & 187,153 & $\mathbf{0 . 0 1}$ \\
Solidity & 0.67 & 0.78 & $<\mathbf{0 . 0 1}$ \\
Dispersion & 0.28 & 0.17 & $<\mathbf{0 . 0 1}$ \\
Closure & 0.98 & 1.00 & $\mathbf{0 . 0 2}$ \\
\hline
\end{tabular}

Land interaction had similar effects on both TCs. Both had increasing areas prior to and during land interaction over Madagascar (Figure 7). Eline exhibited three peaks in area, with the largest occurring before land interaction with Mozambique, while the one peak in Hudah's area occurred over Madagascar and area was at its lowest before landfall over Mozambique. Moving over Madagascar's elevated terrain likely caused the storm center to become exposed and the rain fields more dispersed in both cases, but Hudah recovered quicker (Figure 8). Hudah's center remained enclosed by its rain fields save for when the center moved over land. On the other hand, Eline had only half of its center surrounded by its rain fields at the start of Period 1. Hudah became less dispersed at a rate of $1.9 \mathrm{~km} / \mathrm{h}$ in the $100 \mathrm{~h}$ prior to first land interaction and remained near a value of 0.20 while over the Mozambique Channel. Eline became highly dispersed $36 \mathrm{~h}$ before and $48 \mathrm{~h}$ after first land interaction. However, dispersion then decreased at a rate of $3.4 \mathrm{~km} / \mathrm{h}$ for the next $72 \mathrm{~h}$ as it intensified. There was a difference between the cases for solidity as it decreased markedly while Hudah's center was over land and not at any other time, while for Eline, solidity fluctuated through the study period. When comparing conditions occurring before and after rain fields first interact with land (Table 3), statistically significant differences in values occurred in both storms for asymmetry and dispersion. Eline became more symmetric and less dispersed while Hudah became more asymmetric and dispersed. Significant differences also occurred when Eline increased in area and when Hudah lost solidity and closure. When comparing each storm with the other before and after land interaction (Table 3) as opposed to using the entire study period (Table 4), results are similar for solidity. However, the significant difference in area occurred in Period 2 as Eline grew while Hudah did not, while significant differences in dispersion and closure only occurred in Period 1.

The results of the correlation analyses show that several metrics were highly correlated for both TCs (Table 5). The dispersion values agreed well with the asymmetry calculations, meaning that either method provided useful information about how far the rain fields were offset from the storm center. Area was positively correlated with extent in the NE and SE quadrants. For Hudah, area was positively correlated with extent in all quadrants. The SW quadrant, which typically overlapped with the left front quadrant, exhibited the strongest correlations with area, dispersion, solidity, and closure compared with the other quadrants. The exception was for Eline Period 1 when a greater SW extent meant higher dispersion and closure. Dispersion and asymmetry were negatively correlated with closure as when the rain fields were more displaced towards one side of the storm, it became more difficult for rainfall to completely enclose the storm center, with the exception again being Eline Period 1. Closure and extent towards the SE were also positively correlated in three of four analyses. 


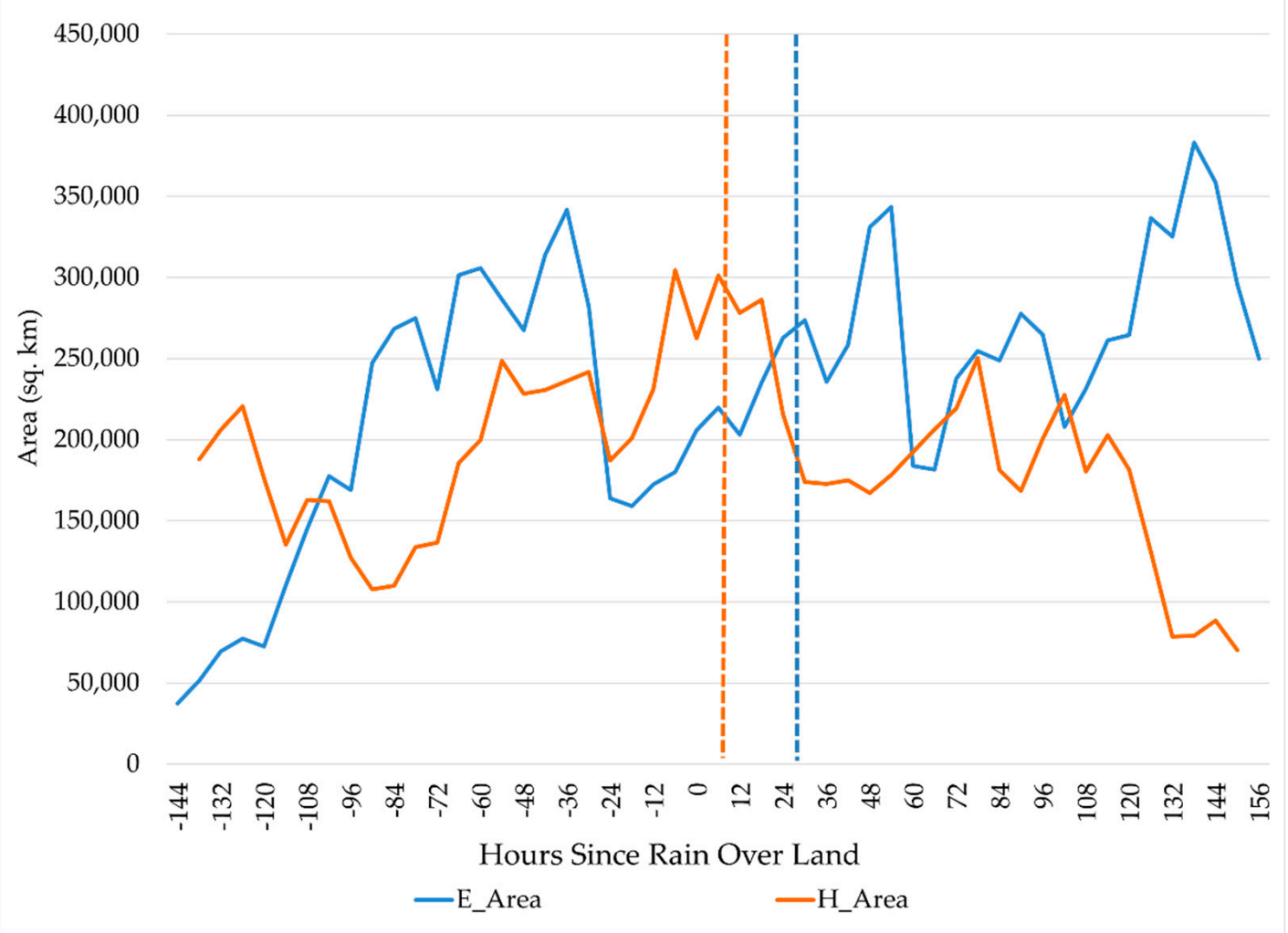

Figure 7. Time series of area (sq. km) for Eline and Hudah for hours since rain began over Madagascar. Vertical dashed lines represent landfall times over Madagascar.

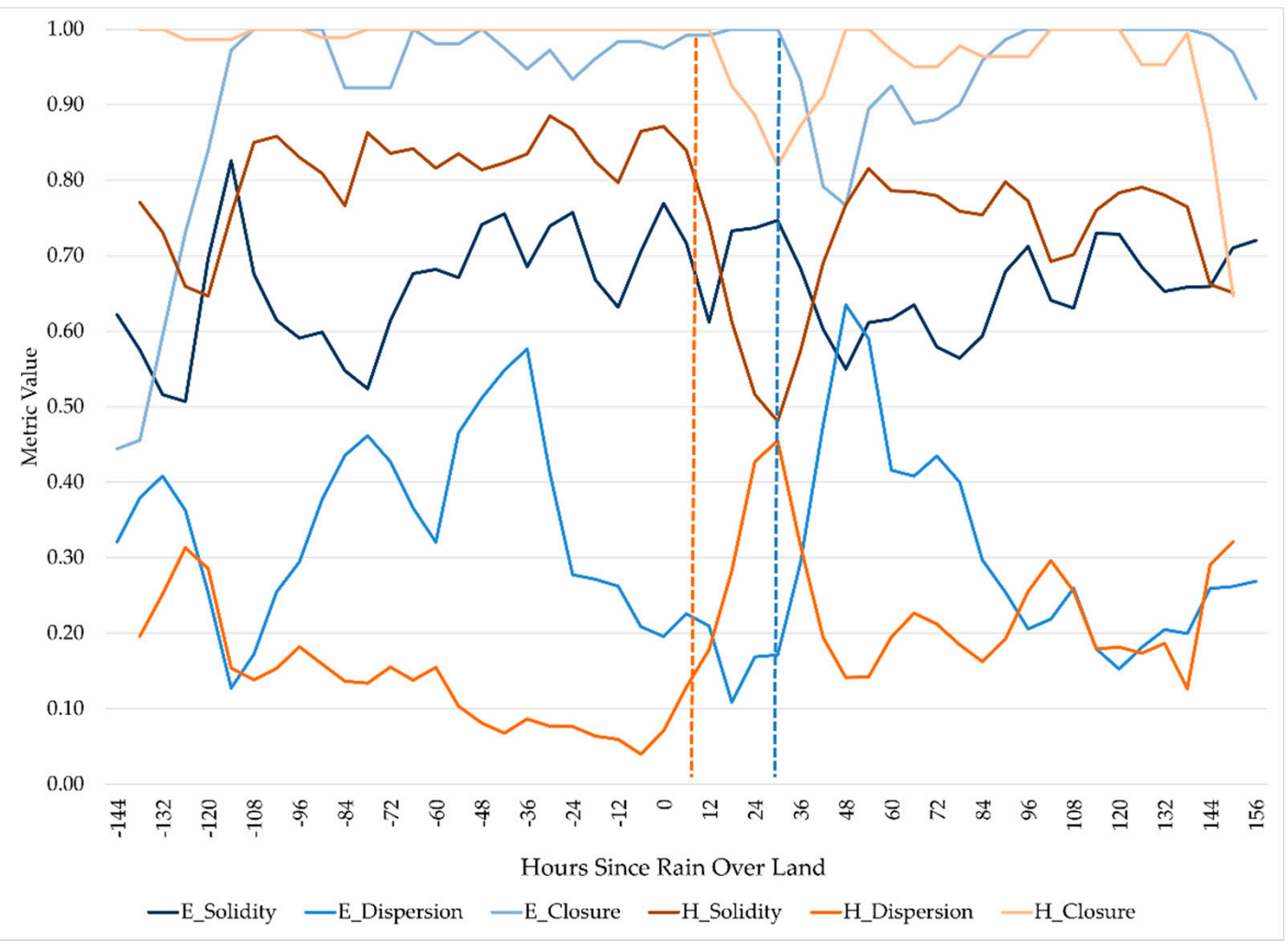

Figure 8. Time series of solidity, dispersion, and closure for Eline and Hudah for hours since rain began over Madagascar. Vertical dashed lines represent landfall times over Madagascar. 
Table 5. Spearman's rank correlation coefficients for (a) Eline and (b) Hudah for rain field measures that were statistically significant at the 0.01 (bold) or 0.05 level in either or both analyses. Top row is for Period 1 and bottom row is for Period 2.

\begin{tabular}{|c|c|c|c|c|}
\hline & & (a) & & \\
\hline Variable & Area & Solidity & Dispersion & Closure \\
\hline \multirow{2}{*}{$\mathrm{NE}$} & 0.42 & \multirow{2}{*}{\multicolumn{2}{|c|}{0.54}} & \\
\hline & 0.42 & & & \\
\hline NW & & 0.45 & -0.62 & 0.65 \\
\hline \multirow{2}{*}{ SW } & 0.87 & \multirow[b]{2}{*}{0.52} & 0.44 & 0.53 \\
\hline & & & -0.60 & 0.6 \\
\hline \multirow{2}{*}{ SE } & 0.87 & & 0.58 & 0.49 \\
\hline & 0.46 & & -0.42 & 0.47 \\
\hline \multirow{2}{*}{ Asymmetry } & 0.69 & \multirow[b]{2}{*}{-0.39} & 0.85 & \\
\hline & & & 0.79 & -0.85 \\
\hline \multirow{2}{*}{ Area } & 1.00 & & & \\
\hline & 1.00 & & & \\
\hline \multirow{2}{*}{ Solidity } & 0.57 & 1.00 & & \\
\hline & & 1.00 & & \\
\hline \multirow{2}{*}{ Dispersion } & & & 1.00 & \\
\hline & & -0.80 & 1.00 & \\
\hline \multirow{2}{*}{ Closure } & 0.44 & \multirow[b]{2}{*}{0.6} & & 1.00 \\
\hline & & & -0.89 & 1.00 \\
\hline \multicolumn{5}{|c|}{ (b) } \\
\hline Variable & Area & Solidity & Dispersion & Closure \\
\hline \multirow{2}{*}{$\mathrm{NE}$} & 0.78 & & & \\
\hline & 0.81 & & & \\
\hline \multirow{2}{*}{ NW } & 0.88 & & -0.65 & 0.46 \\
\hline & 0.45 & & & \\
\hline \multirow{2}{*}{ SW } & 0.7 & 0.51 & -0.73 & 0.54 \\
\hline & 0.73 & 0.46 & -0.42 & 0.73 \\
\hline \multirow{2}{*}{ SE } & 0.48 & & & \\
\hline & 0.79 & & & 0.5 \\
\hline \multirow{2}{*}{ Asymmetry } & -0.52 & -0.45 & 0.78 & -0.42 \\
\hline & & & 0.44 & -0.41 \\
\hline \multirow{2}{*}{ Area } & 1.00 & & & \\
\hline & 1.00 & & & \\
\hline \multirow{2}{*}{ Solidity } & & 1.00 & & \\
\hline & & 1.00 & & \\
\hline \multirow{2}{*}{ Dispersion } & -0.50 & -0.54 & 1.00 & \\
\hline & & -0.71 & 1.00 & \\
\hline \multirow{2}{*}{ Closure } & & 0.65 & -0.48 & 1.00 \\
\hline & & 0.55 & -0.69 & 1.00 \\
\hline
\end{tabular}




\subsection{Environmental Conditions}

For the most part, Eline and Hudah faced different environmental conditions before and after first land interaction and conditions were different when the storms were compared to one another. Although Eline and Hudah took similar paths, they differed significantly in moisture at the $95 \%$ confidence level before and after land interaction (Table 6). Eline moved through an environment with higher values of RH at all three levels even though RH increased for both storms in Period 2 (Figure 9). The SSTs were similar during Period 2 and both TCs saw increased values as compared to Period 1 (Table 6, Figure 10). Despite moving over cooler waters, Hudah was much more intense than Eline during Period 1, but they had similar intensities in Period 2 (Table 6). Eline began the study period as a moderate tropical storm but intensified into a severe tropical storm despite the increasing vertical wind shear. Prior to landfall over Madagascar, Eline was an intense TC while Hudah reached very intense TC status. Likely due to spending less time over land, Hudah regained severe tropical storm status $42 \mathrm{~h}$ after landfall, while it took Eline $60 \mathrm{~h}$ to accomplish this. However, Eline's Mozambique landfall occurred as an intense TC while Hudah only reached TC intensity. The directions and amounts of shear also differed (Table 6, Figure 11). Shear was northerly and strong westerly for Eline in Period 1. It was weaker while moving over Madagascar, strengthening, and becoming more southerly and easterly ahead of its second landfall. For Hudah, zonal and meridional shear remained below $5 \mathrm{~m} / \mathrm{s}$ in Period 1. While moving over the Mozambique Channel, westerly and northerly shear peaked around $5 \mathrm{~m} / \mathrm{s}$, and both decreased ahead of its second landfall. Although shear was higher in Period 2 than during Period 1 for Hudah, values remained relatively low. Both TCs moved slower after land interaction, but their forward speeds were not significantly different from one another.

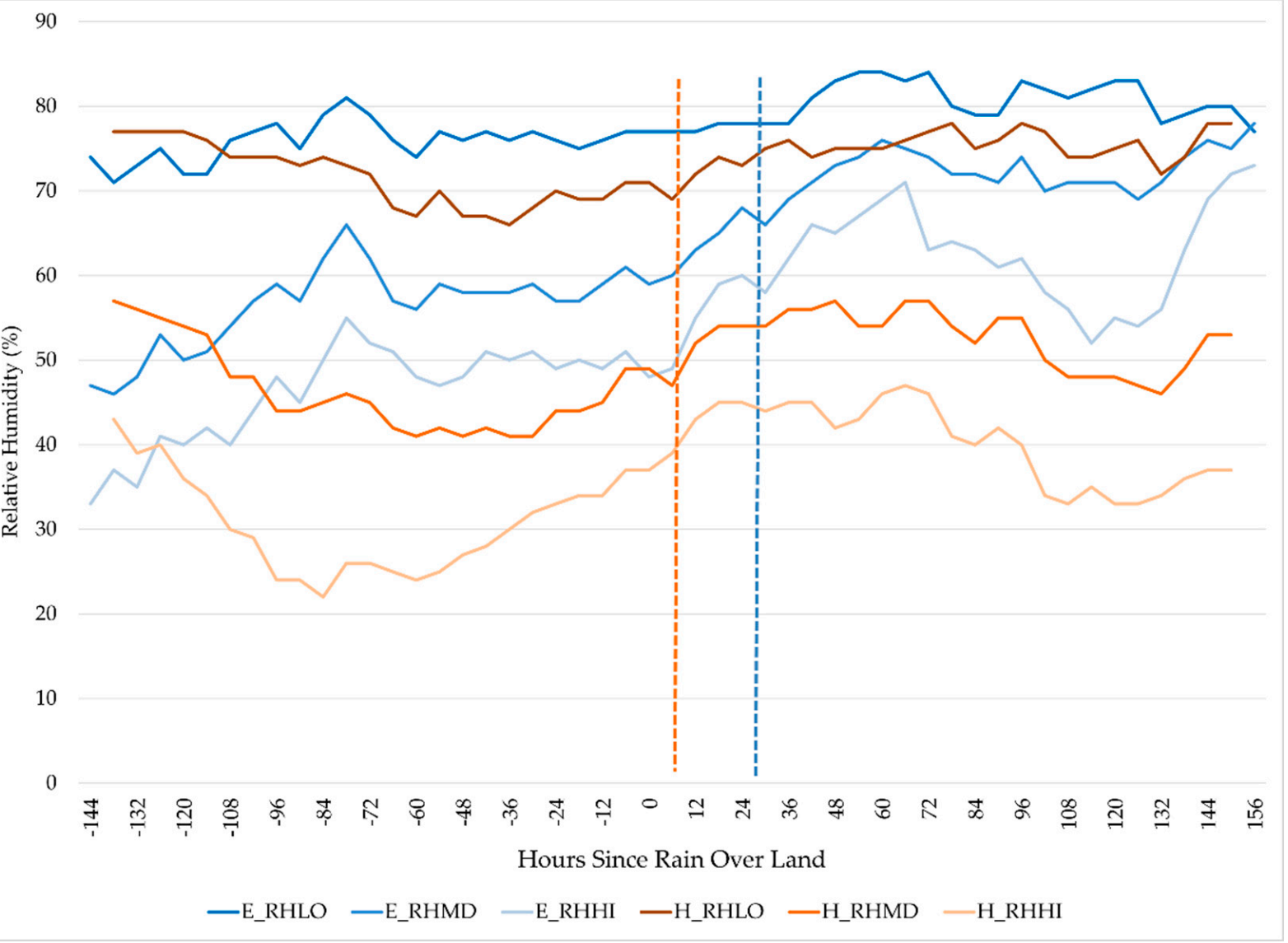

Figure 9. Time series of relative humidity for Eline and Hudah for hours since rain began over Madagascar. Vertical dashed lines represent landfall times over Madagascar. 
Table 6. Median values of environmental conditions for times before and after rain began over Madagascar and $p$-values from Mann-Whitney $U$ tests comparing each storm with itself, the before observations of each storm, and the after observations of each storm. Eline before $n=24$, after $n=27$. Hudah before $n=23$, after $n=26$. Bold values are statistically significant at the 0.01 level.

\begin{tabular}{|c|c|c|c|c|c|c|c|c|}
\hline Variable & $\begin{array}{l}\text { Eline } \\
\text { Per. } 1\end{array}$ & $\begin{array}{l}\text { Eline } \\
\text { Per. } 2\end{array}$ & $\begin{array}{c}\text { Hudah } \\
\text { Per. } 1\end{array}$ & $\begin{array}{c}\text { Hudah } \\
\text { Per. } 2\end{array}$ & $\begin{array}{c}\text { Eline Per. } 1 \\
\text { vs. Per. } 2\end{array}$ & $\begin{array}{l}\text { Hudah Per. } \\
1 \text { vs. Per. } 2\end{array}$ & $\begin{array}{l}\text { Per. } 1 \text { Eline } \\
\text { vs. Hudah }\end{array}$ & $\begin{array}{l}\text { Per. } 2 \text { Eline } \\
\text { vs. Hudah }\end{array}$ \\
\hline $\mathrm{V}_{\max }(\mathrm{m} / \mathrm{s})$ & 43 & 65 & 83 & 68 & $<0.01$ & $<0.01$ & $<0.01$ & 0.62 \\
\hline RHLO (\%) & 76 & 80 & 72 & 75 & $<0.01$ & $<0.01$ & $<0.01$ & $<0.01$ \\
\hline RHMD (\%) & 57 & 71 & 45 & 54 & $<0.01$ & $<0.01$ & $<0.01$ & $<0.01$ \\
\hline RHHI (\%) & 48 & 62 & 30 & 41 & $<0.01$ & $<0.01$ & $<0.01$ & $<0.01$ \\
\hline $\operatorname{SST}\left({ }^{\circ} \mathrm{C}\right)$ & 27.8 & 29.7 & 27.6 & 29.3 & $<0.01$ & $<0.01$ & $<0.01$ & 0.08 \\
\hline Shear V (m/s) & -4.3 & 0.5 & 1.2 & -3.4 & $<0.01$ & $<0.01$ & $<0.01$ & $<0.01$ \\
\hline Shear U (m/s) & 2.6 & 1.0 & 0.4 & 1.9 & 0.05 & $<0.01$ & $<0.01$ & 0.24 \\
\hline Forward Speed (m/s) & 5.4 & 4.1 & 6.2 & 3.3 & $<0.01$ & $<0.01$ & 0.07 & 0.16 \\
\hline
\end{tabular}

Another important environment condition is interaction with land. The amount of interaction with Madagascar differed as Hudah moved across the narrower northern region ( $\sim 350 \mathrm{~km}$ wide) and its center only spent $12 \mathrm{~h}$ over land. Eline moved across the center of the country ( $\sim 500 \mathrm{~km}$ wide) and its center spent $>24 \mathrm{~h}$. over land. Given that Hudah moved across a narrow stretch of the Mozambique Channel ( $450 \mathrm{~km}$ wide) and it took a slow loop $\sim 150 \mathrm{~km}$ offshore before tracking north towards landfall, its rain fields began to move over Mozambique $18 \mathrm{~h}$ after its center emerged over the Channel, and due to its large extent and slow forward speed, rainfall over Mozambique continued for approximately four days before landfall there. In contrast, Eline spent more time over the Mozambique Channel when its slow forward speed was combined with the $1050 \mathrm{~km}$ width of the Channel. Rainfall over Mozambique began only $15 \mathrm{~h}$ prior to landfall there.

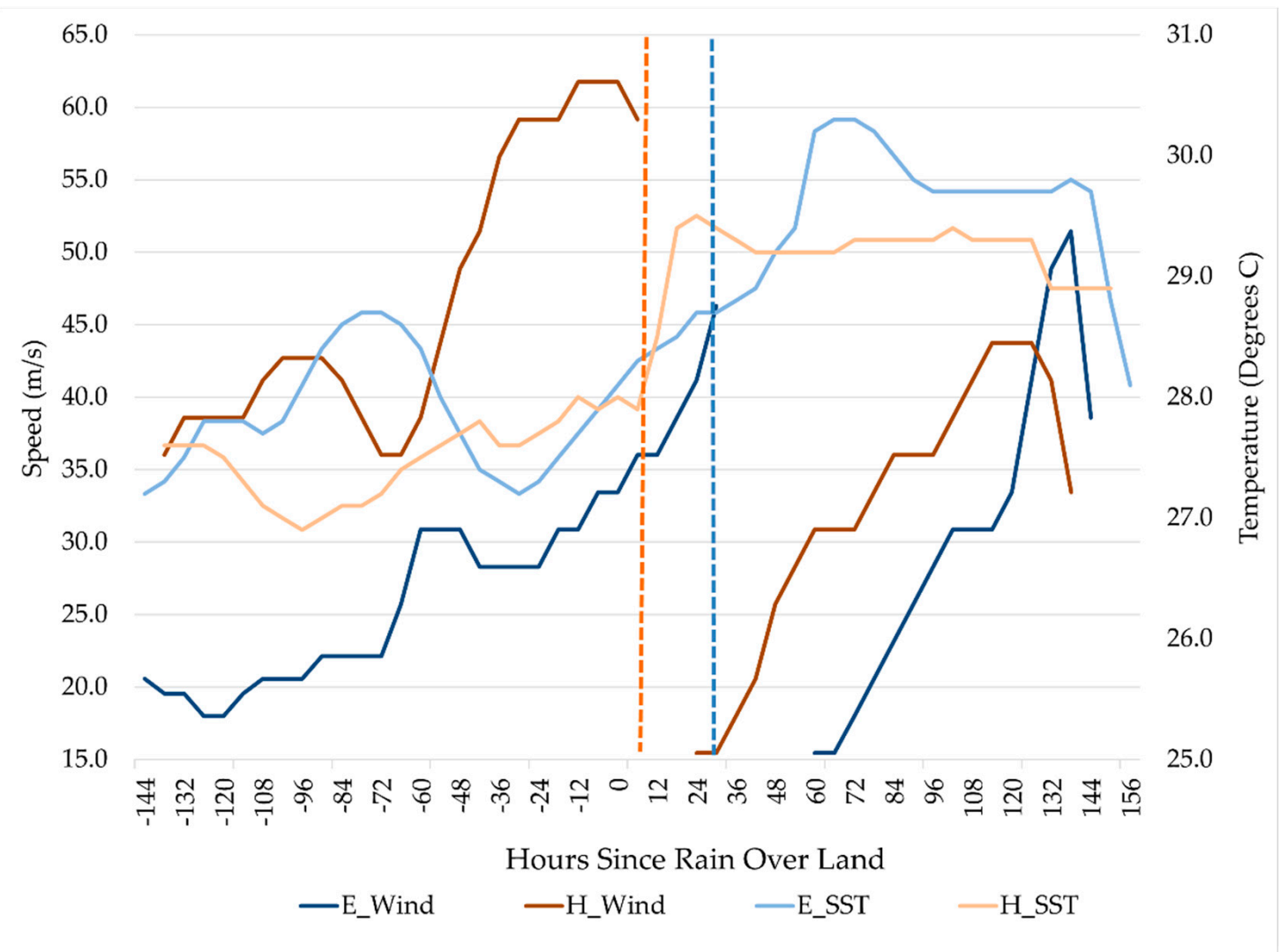

Figure 10. Time series of sea surface temperature (degrees $\mathrm{C}$ ) and speed $(\mathrm{m} / \mathrm{s})$ for Eline and Hudah for hours since rain began over Madagascar. Vertical dashed lines represent landfall times over Madagascar. 


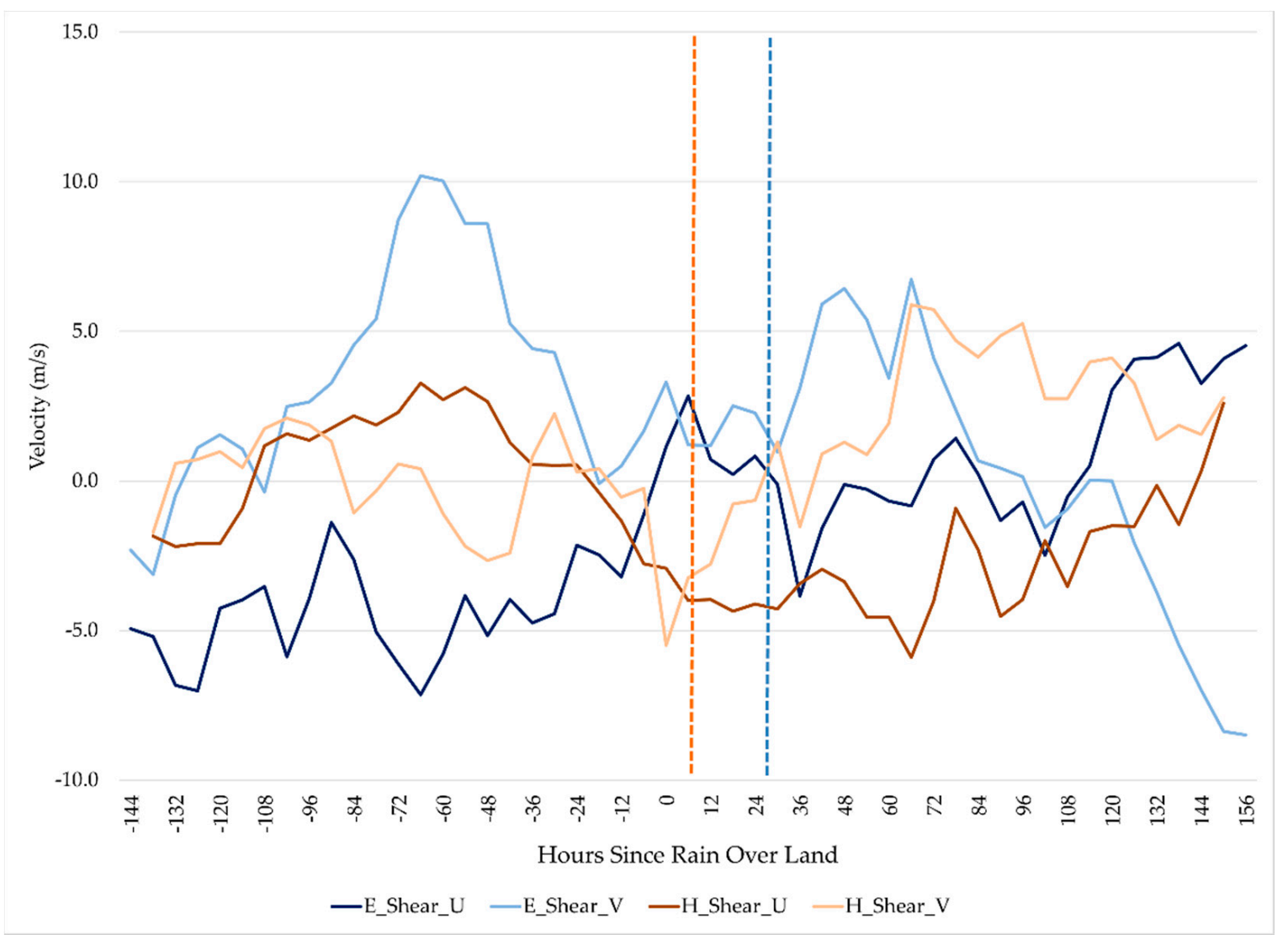

Figure 11. Time series of zonal $(\mathrm{u})$ and meridional $(\mathrm{v})$ wind shear $(\mathrm{m} / \mathrm{s})$ for Eline and Hudah for hours since rain began over Madagascar. Vertical dashed lines represent landfall times over Madagascar.

As previous research $[11,13,54,55]$ has found 12- and 24-h lags between onset of environmental conditions and changes to TC structure, we utilized both lags when calculating Spearman's rank correlation coefficients between the conditions and the rain field metrics. Overall, correlation coefficients were higher when the 12-h lags were utilized as opposed to the 24-h lags and thus we discuss only the results of the 12-h lags. The rain fields of both storms were strongly correlated with storm intensity as higher maximum sustained wind speed correlated positively with extent towards the SW, solidity, and closure and negatively with dispersion and asymmetry (Table 7). Both storms were more asymmetric and had larger SE extent when shear was westerly and northerly, placing SE in the downshear right quadrant. While increased RH and SSTs coincided with farther extent towards the NW and NE in Eline, moisture was more strongly related to NE extent and rain field shape in Hudah with higher amounts of moisture corresponding to higher dispersion and lower solidity and closure. Higher dispersion and less solidity could be the result of outer rainbands forming in the environment with higher moisture. Higher moisture for Hudah occurred during Period 2 when Hudah interacted with land most of the time, and land interaction could explain the unexpected sign of the coefficient for closure as one would expect closure and moisture to be positively correlated. While Eline had higher closure and solidity and lower dispersion closer to landfall (Figure 8), Hudah exhibited these characteristics when forward velocity was greater, a time corresponding to Period 1. 
Table 7. Spearman's rank correlation coefficients between storm conditions and rain field metrics 12-h later using data for the entire study period. Only values significant at 0.05 and 0.01 (bold) are included. Top row is for Eline and bottom row is for Hudah.

\begin{tabular}{|c|c|c|c|c|c|c|c|c|c|}
\hline Variable & $\mathrm{V}_{\max }$ & RHLO & RHMD & RHHI & RSST & Shear V & Shear U & Speed & $\begin{array}{c}\text { Dist. } \\
\text { Landfall }\end{array}$ \\
\hline \multirow{2}{*}{$\mathrm{NE}$} & & 0.60 & 0.60 & 0.54 & 0.64 & 0.32 & & -0.31 & -0.48 \\
\hline & & & 0.46 & 0.60 & 0.31 & -0.63 & & & \\
\hline \multirow{2}{*}{ NW } & 0.37 & 0.62 & 0.77 & 0.76 & 0.65 & 0.74 & & & -0.71 \\
\hline & & -0.45 & & & & & -0.52 & 0.49 & \\
\hline \multirow{2}{*}{ SW } & 0.68 & & & & & & & & -0.31 \\
\hline & 0.60 & -0.52 & -0.40 & & & & & & -0.30 \\
\hline \multirow{2}{*}{ SE } & & & & & & -0.29 & 0.34 & & \\
\hline & & & & & & -0.43 & & & \\
\hline \multirow{2}{*}{ Asym. } & -0.45 & & & & & -0.52 & 0.62 & & \\
\hline & -0.69 & 0.63 & 0.66 & 0.42 & 0.39 & -0.42 & 0.37 & -0.42 & \\
\hline \multirow{2}{*}{ Area } & & 0.32 & 0.48 & 0.57 & & & & -0.31 & -0.57 \\
\hline & & & & 0.35 & 0.37 & -0.46 & & & \\
\hline \multirow{2}{*}{ Solidity } & 0.54 & & & & -0.28 & & & & -0.41 \\
\hline & 0.59 & -0.60 & -0.61 & -0.39 & -0.37 & 0.35 & -0.40 & 0.53 & \\
\hline \multirow{2}{*}{ Disp. } & -0.57 & & & & & -0.41 & 0.48 & & 0.30 \\
\hline & -0.62 & 0.62 & 0.52 & & 0.35 & & 0.41 & -0.61 & \\
\hline \multirow{2}{*}{ Closure } & 0.64 & & & & & 0.35 & & & -0.44 \\
\hline & 0.66 & -0.55 & -0.56 & -0.38 & -0.37 & & -0.37 & 0.50 & \\
\hline
\end{tabular}

\section{Discussion}

We now compare the spatial dimensions of the rain fields for Eline and Hudah to studies of Atlantic basin TCs. The two most comparable studies in terms of data utilized TRMM 3B42 rain rates yet selected $2.5 \mathrm{~mm} / \mathrm{h}$ to define the rain field edge. Eline and Hudah had larger mean areas than the 35 TCs in [49] likely due to the lower threshold of $1 \mathrm{~mm} / \mathrm{h}$ used to define the rain field edge. Interestingly, Eline's dispersion values are comparable to this previous study, which also found that more intense TCs were less dispersed. Zhou et al. [13] measured area and extent of 70 TCs within $600 \mathrm{~km}$ of the U.S. coastline. Although Eline and Hudah covered more area than these TCs, their rain fields did not extend as far away from center. This difference could be explained by the fact that dry air tends to advect into TCs near landfall over large land masses, reducing areal coverage of rain rates [56,57]. However, higher rain rates in outer rainbands may still occur causing extent to remain high. An analysis of solidity for these 70 TCs would help confirm this hypothesis.

Three previous studies employed reflectivity values from ground-based weather radars to measure TC rain field properties, selecting a $20 \mathrm{dBZ}$ threshold to define the storm's outer edge. When converting radar reflectivity to rain rate in a tropical environment this equates to $0.5 \mathrm{~mm} / \mathrm{h} \mathrm{[58]}$. According to [11], U.S. landfalling hurricanes have average rain field extents of $223 \mathrm{~km}$ which agrees well with the results of the current study. However, those hurricanes had higher values of asymmetry as compared to Hudah and Eline and were moving through environments containing less moisture. Matyas and Tang [50] found strong negative correlations between dispersion and closure ( -0.93 and -0.75$)$, and values for these metrics covered a larger range than in the current study as those TCs moved inland. Rain field areas were lower for the TCs in [50] but both experienced strong vertical wind shear and became highly asymmetric after landfall while also experiencing dry 
air entrainment that likely accounted for the smaller area values. Similarly, Hurricane Isabel (2003) [52] experienced strong vertical wind shear and dry air entrainment while undergoing extratropical transition exhibiting higher dispersion and lower closure, with a stronger correlation between these metrics, as compared to the current study. Results from [53] agree with the current study that more intense TCs are more enclosed by their rain fields. Overall, the current study's finding that closure and dispersion were correlated with TC intensity helps to validate previous research, while differences in actual values as well as area and extent could be explained by Eline and Hudah's high intensity, moving through an environment with relatively low vertical wind shear and high moisture, and not being sampled at a time when they moved far inland as was the case for the previous ground-based radar studies.

The speed and direction of the vertical wind shear was a large difference between the storms. According to [19], deep-layer vertical shear is normally quite low in the area that Hudah transited and climatologically is slightly higher with a westerly direction where Eline passed. Their analysis showed a downshear right asymmetry in TC rain fields for cases in the basin. Deep-layer VWS is considered to be high and most damaging to a TC's structure when its velocity is $>10 \mathrm{~m} / \mathrm{s}$ [18]. Hudah never experienced shear of this magnitude, while Eline experienced it for $24 \mathrm{~h}$ three days before rain began over land. This timing corresponds to increasing extent towards the SE, or downshear right quadrant, and higher dispersion. In fact, Period 1 dispersion peaked $12 \mathrm{~h}$ after this period of high shear. Hudah experienced weak shear $(<5 \mathrm{~m} / \mathrm{s}) 88 \%$ of the time while Eline experienced weak shear $53 \%$ of the time when both periods are considered. Much of the weak shear for Eline occurred during Period 2, corresponding to increased extent towards the north and overall areal coverage, and decreasing asymmetry and dispersion.

The high RH values may also have been an important difference between the storms. Despite the northwesterly shear likely causing Eline to become asymmetrical and dispersed in Period 1, closure remained high. This could have been due to the abundance of moisture which helped rain rates to remain high as the intensifying storm converged more moisture into its core that then circulated around the storm center. Matyas and Tang [50] found that closure remained high despite strong vertical wind shear as Hurricane Humberto (2007) moved through an environment containing high amounts of moisture. The increase in moisture may also have helped Hudah maintain its rain field extent after its first landfall even though shear velocity did significantly increase as well. Despite experiencing lower RH overall, Hudah maintained a higher solidity. This could have been due to its higher intensity allowing it to be more efficient in converging available moisture into its core. Previous research has found that TCs can grow larger when moving through environments with higher RH [21], but this large extent could be more difficult to keep filled with rain when intensity is lower and vertical wind shear is stronger. However, the higher moisture may have facilitated the rapid recovery in rain field area after Eline's first landfall, allowing it to reach its greatest coverage prior to Mozambique landfall when it also attained its highest intensity. In [11], a larger extent of hurricane rain fields occurred with higher values of RH and thus the current study supports this finding.

Overall, the metrics exhibited the strongest and most consistent relationships with storm intensity so that a more intense TC had larger extent in the SW, or left front, quadrant, was more symmetrical and filled by rain that more completely encompassed the storm center, and rain was more centered around the storm. It should be noted that values of these metrics changed the most rapidly due to land interaction, which in turn also caused TC winds to weaken. So, it is not possible to conclude whether intensity changes in the absence of landfall would exhibit the same strong relationships with storm shape that were observed here.

The results underscore the importance of considering how TCs which make multiple landfalls respond to interaction with land. Hudah was more intense and spent less time over Madagascar. Dispersion, closure, and solidity show that Hudah recovered quite quickly once moving back over water compared to Eline, which spent more than twice as 
long over Madagascar and was less intense prior to landfall. Dividing the observations into the two periods also highlighted the differences in SSTs, RH, and VWS experienced by each TC. Although SSTs and RH increased in both cases, shear decreased for Eline and increased for Hudah, although not to the level that Eline experienced during Period 1. Thus, crossing over Madagascar can allow TCs to emerge over the Mozambique Channel into different environmental conditions which can in turn affect the organization of their rain fields.

\section{Conclusions}

This study examined atmospheric conditions and rainfall extent in cyclones Eline and Hudah which both made landfall over Madagascar and Mozambique in 2000. Satellitebased estimates of rain rates were analyzed to measure the spatial properties of their rain fields as defined by $1 \mathrm{~mm} / \mathrm{h}$ rain rates. Metrics calculated included averaged rain field extent in each quadrant and asymmetry, areal coverage, solidity, dispersion, and closure. Storm intensity and environmental conditions experienced by each TC including vertical wind shear, relative humidity, sea surface temperatures, and proximity to land were also examined every six hours to determine whether these conditions varied between the storms and might have contributed to differences in rainfall distribution using nonparametric statistical tests. Observations were examined separately for the hours prior to and after each TC's first interaction with Madagascar.

Eline and Hudah both intensified before each of their respective landfalls. Despite moving over warmer waters and through an atmosphere with higher RH, Eline was a weaker TC prior to first landfall as it experienced stronger VWS compared to Hudah. The rain fields of Hudah were more symmetrical, had a larger extent towards the north, were more closed and solid, and less dispersed than Eline prior to first interaction with land. Although both TCs encountered increased moisture and SSTs, re-intensified, and had slower forward velocities after first landfall, the amount and direction of shear differed as did the duration of land interaction after first encountering Madagascar. In that second period, dispersion and closure were similar between the storms as was rain field extent in most quadrants suggesting that moving over land and then into an environment of relatively low shear and high moisture had similar effects on rain field structure. The rain fields of both TCs exhibited strong correlations with intensity when a 12-h lag was applied between storm conditions and rain field metrics. Higher maximum sustained wind speed corresponded to larger extent towards the SW, less asymmetry and dispersion, and being more enclosed and solid. Relationships between intensity and rain field shape support the results of previous research and demonstrate the global utility of these metrics.

Future research should expand on the limited scope of this exploratory study. A larger sample of TCs that originated over the SWIO should be analyzed to provide a more holistic analysis of rain fields in this basin to facilitate comparisons to TCs in other basins. In particular, we found that rainfall can begin over land $9 \mathrm{~h}$ to $>4$ days before landfall depending on the extent of the rain fields in the forward quadrants and storm forward speed. It would be useful to characterize other landfalling TCs in this manner to provide better estimates on the timing of preparations for rain to begin in future storms. This study demonstrates the utility of spatial metrics to measure changes in rain field distributions before and after TCs interact with a large mountainous island, which suggests that additional TCs should be explored in this way, both in the SWIO and in other basins. More recent TCs should be analyzed using data from the Global Precipitation Mission satellite's sensors that provide increased spatial and temporal resolution to better resolve the influences of land interaction. Additional rain rate thresholds could also be employed to distinguish changes in lower and higher rain rates.

Author Contributions: Conceptualization, S.V. and C.J.M.; methodology, C.J.M.; analysis, S.V., C.J.M.; writing-original draft preparation, S.V.; writing - review and editing S.V. and C.J.M.; visualization, S.V. and C.J.M.; supervision, C.J.M.; funding acquisition, C.J.M. All authors have read and agreed to the published version of the manuscript. 
Funding: For initial stages of this work, S.V. was supported by the National Science Foundation ICER-1540729 and C.J.M. was supported by the National Science Foundation ICER-1540724. No funds were received to cover publication costs.

Data Availability Statement: Publicly-available datasets were analyzed in this study. These data can be found here: TRMM 3B42: https:/ /gpm.nasa.gov/data/directory; SHIPS: ftp:/ /ftp.nhc.noaa. gov / atcf/archive; IBTrACS: https:/ / www.ncdc.noaa.gov/ibtracs/index.php?name=ib-v4-access.

Conflicts of Interest: The authors declare no conflict of interest. The funders had no role in the design of the study; in the collection, analyses, or interpretation of data; in the writing of the manuscript, or in the decision to publish the results.

\section{References}

1. Mulugeta, G.; Durrheim, R.; Ayonghe, S.; Daby, D.; Dube, O.P.; Gudyanga, F.; Lucio, F. ICSU ROA'S Science Plan to Address Natural and Human-Induced Encironmental Hazards and Disasters in Sub-Saharan Africa; International Council for Science: Pretoria, South Africa, 2007; p. 27.

2. Rappaport, E.N. Fatalities in the United States from Atlantic Tropical Cyclones: New Data and Interpretation. Bull. Am. Meteorol. Soc. 2014, 95, 341-346. [CrossRef]

3. Dvorak, V.F. Tropical Cyclone Intensity Analysis and Forecasting from Satellite Imagery. Mon. Weather Rev. 1975, 103, 420-430. [CrossRef]

4. Emerton, R.; Cloke, H.; Ficchi, A.; Hawker, L.; De Wit, S.; Speight, L.; Prudhomme, C.; Rundell, P.; West, R.; Neal, J.; et al. Emergency flood bulletins for Cyclones Idai and Kenneth: A critical evaluation of the use of global flood forecasts for international humanitarian preparedness and response. Int. J. Disaster Risk Reduct. 2020, 50, 101811. [CrossRef]

5. Kolstad, E.W. Prediction and precursors of Idai and 38 other tropical cyclones and storms in the Mozambique Channel. Q. J. R. Meteorol. Soc. 2020. [CrossRef]

6. Mavume, A.; Rydberg, L.; Rouault, M.; Lutjeharms, J. Climatology and Landfall of Tropical Cyclones in the South- West Indian Ocean. West. Indian Ocean J. Mar. Sci. 2010, 8. [CrossRef]

7. Kruger, L. The timing of agricultural production in hazard-prone areas to prevent losses at peak-risk periods: A case of Malawi, Madagascar and Mozambique. Jàmbá J. Dis. Risk Stud. 2016, 8, 179. [CrossRef]

8. Matyas, C.J.; Silva, J.A. Extreme weather and economic well-being in rural Mozambique. Nat. Hazards 2013, 66, 31-49. [CrossRef]

9. Reason, C.J.C.; Hachigonta, S.; Phaladi, R.F. Interannual variability in rainy season characteristics over the Limpopo region of southern Africa. Int. J. Clim. 2005, 25, 1835-1853. [CrossRef]

10. Washington, R.; Preston, A. Extreme wet years over southern Africa: Role of Indian Ocean sea surface temperatures. J. Geophys. Res. Space Phys. 2006, 111. [CrossRef]

11. Matyas, C.J. Associations between the size of hurricane rain fields at landfall and their surrounding environments. Theor. Appl. Clim. 2010, 106, 135-148. [CrossRef]

12. Matyas, C.J. Processes Influencing Rain-Field Growth and Decay after Tropical Cyclone Landfall in the United States. J. Appl. Meteorol. Clim. 2013, 52, 1085-1096. [CrossRef]

13. Zhou, Y.; Matyas, C.; Li, H.; Tang, J. Conditions associated with rain field size for tropical cyclones landfalling over the Eastern United States. Atmos. Res. 2018, 214, 375-385. [CrossRef]

14. Arivelo, T.A.; Lin, Y.-L. Climatology of Heavy Orographic Rainfall Induced by Tropical Cyclones over Madagascar: From Synoptic to Mesoscale Perspectives. Earth Sci. Res. 2016, 5, 146-161. [CrossRef]

15. Gray, W.M. Global view of the origin of tropical disturbances and storms. Mon. Weather Rev. 1968, 96, 669-700. [CrossRef]

16. Wingo, M.T.; Cecil, D.J. Effects of Vertical Wind Shear on Tropical Cyclone Precipitation. Mon. Weather Rev. 2010, 138, 645-662. [CrossRef]

17. Lonfat, M.; Rogers, R.; Marchok, T.; Marks, F.D. A Parametric Model for Predicting Hurricane Rainfall. Mon. Weather Rev. 2007, 135, 3086-3097. [CrossRef]

18. Corbosiero, K.L.; Molinari, J. The Effects of Vertical Wind Shear on the Distribution of Convection in Tropical Cyclones. Mon. Weather Rev. 2002, 130, 2110-2123. [CrossRef]

19. Chen, S.S.; Knaff, J.A.; Marks, F.D. Effects of Vertical Wind Shear and Storm Motion on Tropical Cyclone Rainfall Asymmetries Deduced from TRMM. Mon. Weather Rev. 2006, 134, 3190-3208. [CrossRef]

20. Lonfat, M.; Marks, F.D.; Chen, S.S. Precipitation Distribution in Tropical Cyclones Using the Tropical Rainfall Measuring Mission (TRMM) Microwave Imager: A Global Perspective. Mon. Weather Rev. 2004, 132, 1645-1660. [CrossRef]

21. Hill, K.A.; Lackmann, G.M. Influence of Environmental Humidity on Tropical Cyclone Size. Mon. Weather Rev. 2009, 137, 3294-3315. [CrossRef]

22. Braun, S.A.; Sippel, J.A.; Nolan, D.S. The Impact of Dry Midlevel Air on Hurricane Intensity in Idealized Simulations with No Mean Flow. J. Atmos. Sci. 2012, 69, 236-257. [CrossRef]

23. Bretherton, C.S.; Peters, M.E.; Back, L.E. Relationships between water vapor path and precipitation over the tropical oceans. J. Clim. 2004, 17, 1517-1528. [CrossRef] 
24. Evans, J.L.; Ryan, B.F.; McGregor, J.L. A Numerical Exploration of the Sensitivity of Tropical Cyclone Rainfall Intensity to Sea Surf@ace Temperature. J. Clim. 1994, 7, 616-623. [CrossRef]

25. Lin, Y.; Zhao, M.; Zhang, M. Tropical cyclone rainfall area controlled by relative sea surface temperature. Nat. Commun. 2015, 6, 1-7. [CrossRef]

26. Jury, M.R.; Pathack, B. A study of climate and weather variability over the tropical southwest Indian Ocean. Theor. Appl. Clim. 1991, 47, 37-48. [CrossRef]

27. Jury, M.R.; Mc Queen, C.; Levey, K. SOI and QBO signals in the African region. Theor. Appl. Clim. 1994, 50, 103-115. [CrossRef]

28. Williams, C.J.R.; Kniveton, D.R.; Layberry, R. Climatic and oceanic associations with daily rainfall extremes over Southern Africa. Int. J. Clim. 2006, 27, 93-108. [CrossRef]

29. Naeraa, M.; Jury, M.R. Tropical cyclone composite structure and impacts over eastern Madagascar during January-March 1994. Meteorol. Atmos. Phys. 1998, 65, 43-53. [CrossRef]

30. Matyas, C.J. Tropical cyclone formation and motion in the Mozambique Channel. Int. J. Clim. 2014, 35, 375-390. [CrossRef]

31. Usman, M.; Reason, C. Dry spell frequencies and their variability over southern Africa. Clim. Res. 2004, 26, 199-211. [CrossRef]

32. Brida, A.B.; Owiyo, T.; Sokona, Y. Loss and damage from the double blow of flood and drought in Mozambique. Int. J. Glob. Warm. 2013, 5, 514-531. [CrossRef]

33. Reason, C.J.C.; Keibel, A. Tropical Cyclone Eline and Its Unusual Penetration and Impacts over the Southern African Mainland. Weather Forecast. 2004, 19, 789-805. [CrossRef]

34. Ash, K.D.; Matyas, C.J. The influences of ENSO and the subtropical Indian Ocean Dipole on tropical cyclone trajectories in the southwestern Indian Ocean. Int. J. Clim. 2010, 32, 41-56. [CrossRef]

35. Fitchett, J.M.; Grab, S.W. A 66-year tropical cyclone record for south-east Africa: Temporal trends in a global context. Int. J. Clim. 2014, 34, 3604-3615. [CrossRef]

36. Vitart, F.; Anderson, D.; Stockdale, T. Seasonal Forecasting of Tropical Cyclone Landfall over Mozambique. J. Clim. 2003, 16, 3932-3945. [CrossRef]

37. FAO/GIEWS Special Alert No. 301: Southern Africa (3 March 2000)-Mozambique, ReliefWeb. Available online: https: / / reliefweb.int/report/mozambique/faogiews-special-alert-no-301-southern-africa-3-march-2000 (accessed on 28 December 2020).

38. Du Plessis, L. A review of effective flood forecasting, warning and response system for application in South Africa. Water $S A$ 2002, 28, 129-138. [CrossRef]

39. SPECIAL REPORT: Madagascar-12 April. Available online: http://www.fao.org/3/x4973e/x4973e00.htm (accessed on 28 December 2020).

40. Stampoulis, D.; Haddad, Z.S.; Anagnostou, E.N. Assessing the drivers of biodiversity in Madagascar by quantifying its hydrologic properties at the watershed scale. Remote. Sens. Environ. 2014, 148, 1-15. [CrossRef]

41. Huffman, G.J.; Bolvin, D.T.; Nelkin, E.J.; Wolff, D.B.; Adler, R.F.; Gu, G.; Hong, Y.; Bowman, K.P.; Stocker, E.F. The TRMM Multisatellite Precipitation Analysis (TMPA): Quasi-Global, Multiyear, Combined-Sensor Precipitation Estimates at Fine Scales. J. Hydrometeorol. 2007, 8, 38-55. [CrossRef]

42. Jiang, H.; Liu, C.; Zipser, E.J. A TRMM-Based Tropical Cyclone Cloud and Precipitation Feature Database. J. Appl. Meteorol. Clim. 2011, 50, 1255-1274. [CrossRef]

43. Prat, O.P.; Nelson, B.R. Mapping the world's tropical cyclone rainfall contribution over land using the TRMM Multi-satellite Precipitation Analysis. Water Resour. Res. 2013, 49, 7236-7254. [CrossRef]

44. Blamey, R.C.; Reason, C.J.C. The Role of Mesoscale Convective Complexes in Southern Africa Summer Rainfall. J. Clim. 2013, 26, 1654-1668. [CrossRef]

45. Knapp, K.R.; Kruk, M.C.; Levinson, D.H.; Diamond, H.J.; Neumann, C.J. The International Best Track Archive for Climate Stewardship (IBTrACS). Bull. Am. Meteorol. Soc. 2010, 91, 363-376. [CrossRef]

46. DeMaria, M.; Mainelli, M.; Shay, L.K.; Knaff, J.A.; Kaplan, J. Further Improvements to the Statistical Hurricane Intensity Prediction Scheme (SHIPS). Weather Forecast. 2005, 20, 531-543. [CrossRef]

47. Guo, Q.; Matyas, C.J. Comparing the spatial extent of Atlantic basin tropical cyclone wind and rain fields prior to land interaction. Phys. Geogr. 2016, 37, 5-25. [CrossRef]

48. AghaKouchak, A.; Nasrollahi, N.; Li, J.; Imam, B.; Sorooshian, S. Geometrical Characterization of Precipitation Patterns. J. Hydrometeorol. 2011, 12, 274-285. [CrossRef]

49. Zhou, Y.; Matyas, C.J. Spatial Characteristics of Rain Fields Associated with Tropical Cyclones Landfalling over the Western Gulf of Mexico and Caribbean Sea. J. Appl. Meteorol. Clim. 2018, 57, 1711-1727. [CrossRef]

50. Matyas, C.; Tang, J. Measuring Radial and Tangential Changes in Tropical Cyclone Rain Fields Using Metrics of Dispersion and Closure. Adv. Meteorol. 2019, 2019, 1-14. [CrossRef]

51. Zick, S.E.; Matyas, C.J. A Shape Metric Methodology for Studying the Evolving Geometries of Synoptic-Scale Precipitation Patterns in Tropical Cyclones. Ann. Am. Assoc. Geogr. 2016, 106, 1217-1235. [CrossRef]

52. Matyas, C.J.; Zick, S.E.; Tang, J. Using an Object-Based Approach to Quantify the Spatial Structure of Reflectivity Regions in Hurricane Isabel (2003). Part I: Comparisons between Radar Observations and Model Simulations. Mon. Weather Rev. 2018, 146, 1319-1340. [CrossRef]

53. Matyas, C. Quantifying the Shapes of U.S. Landfalling Tropical Cyclone Rain Shields*. Prof. Geogr. 2007, 59, 158-172. [CrossRef] 
54. Frank, W.M.; Ritchie, E.A. Effects of Environmental Flow upon Tropical Cyclone Structure. Mon. Weather Rev. 1999, 127, $2044-2061$. [CrossRef]

55. Jiang, H.; Halverson, J.B.; Zipser, E.J. Influence of environmental moisture on TRMM-derived tropical cyclone precipitation over land and ocean. Geophys. Res. Lett. 2008, 35. [CrossRef]

56. Cubukcu, N.; Pfeffer, R.L.; Dietrich, D.E. Simulation of the Effects of Bathymetry and Land-Sea Contrasts on Hurricane Development Using a Coupled Ocean-Atmosphere Model. J. Atmos. Sci. 2000, 57, 481-492. [CrossRef]

57. Chan, J.C.L.; Liang, X. Convective Asymmetries Associated with Tropical Cyclone Landfall. Part I: F-Plane Simulations. J. Atmos. Sci. 2003, 60, 1560-1576. [CrossRef]

58. Rosenfeld, D.; Wolff, D.B.; Atlas, D. General Probability-matched Relations between Radar Reflectivity and Rain Rate. J. Appl. Meteorol. 1993, 32, 50-72. [CrossRef] 